University of Wollongong

Research Online

Faculty of Engineering and Information

Faculty of Engineering and Information

Sciences - Papers: Part B

Sciences

2019

Experimental study to examine the role of under sleeper pads for improved performance of ballast under cyclic loading

Wickramarachchi Withanage Chamindi Jayasuriya

University of Wollongong, chamindi@uow.edu.au

Buddhima Indraratna

University of Wollongong, indra@uow.edu.au

Ngoc Trung Ngo

University of Wollongong, trung@uow.edu.au

Follow this and additional works at: https://ro.uow.edu.au/eispapers1

Part of the Engineering Commons, and the Science and Technology Studies Commons

Research Online is the open access institutional repository for the University of Wollongong. For further information contact the UOW Library: research-pubs@uow.edu.au 


\title{
Experimental study to examine the role of under sleeper pads for improved performance of ballast under cyclic loading
}

\author{
Abstract \\ The degradation and deformation of ballast critically affect the track geometry, safety, and passenger \\ comfort. The increase in axle loads and train speed increases the stress applied on the ballast and \\ exacerbates the rate of ballast degradation. This situation is more critical when tracks are built on stiff \\ subgrades (e.g. bridges, tunnels and crossings), hence the use of energy absorbing (damping) layers in \\ track substructure is a countermeasure to minimize track damage. In this study, a series of large-scale \\ laboratory tests using the track process simulation testing apparatus (TPSA) is carried out to assess the \\ performance of under sleeper pads (USP) to reduce ballast degradation and to decrease permanent \\ deformation. When placed beneath the sleeper, the energy absorbing nature of USP reduces the energy \\ transferred to the ballast and other substructure components. Subsequently, the ballast layer experiences \\ less deformation and degradation. Innovative tactile surface sensors (matrix-based) are used to measure \\ the pressure and contact area between sleeper and ballast. The measured data show that an increase in \\ contact area between sleeper and ballast decreases the stress applied on ballast, and thus a reduction in \\ ballast breakage and corresponding reduced ballast deformation can be achieved. Furthermore, the \\ influence of the USP stiffness is examined and the measured data offer an insightful understanding of the \\ role of USP for given track and loading conditions in terms of energy dissipation and reduced ballast \\ deformation.

\section{Disciplines} \\ Engineering | Science and Technology Studies
}

\section{Publication Details}

Jayasuriya, C., Indraratna, B. \& Ngo, T. (2019). Experimental study to examine the role of under sleeper pads for improved performance of ballast under cyclic loading. Transportation Geotechnics, 19 61-73. 


\section{Experimental Study to Examine the Role of Under Sleeper Pads for Improved Performance of Ballast under Cyclic Loading}

\section{Chamindi Jayasuriya}

PhD Student, Centre for Geomechanics and Railway Engineering (CGRE) and ARC Training Centre for Advanced Technologies in Rail Track Infrastructure (ITTC-Rail), University of Wollongong Australia, NSW 2522, Australia.

\section{Buddhima Indraratna, PhD, FTSE, FASCE, FIEAust, FGS}

Distinguished Professor of Civil Engineering; Research Director, Centre for Geomechanics and Railway Engineering (CGRE) and ARC Training Centre for Advanced Technologies in Rail Track Infrastructure (ITTCRail), University of Wollongong Australia, NSW 2522, Australia.

\section{Trung Ngoc Ngo, PhD, MIEAust}

Research Fellow, Centre for Geomechanics and Railway Engineering (CGRE) and ARC Training Centre for Advanced Technologies in Rail Track Infrastructure (ITTC-Rail), University of Wollongong Australia, NSW 2522, Australia.

Technical paper submitted to: Transportation Geotechnics

Authors for correspondence:

Distinguished Professor Buddhima Indraratna Faculty of Engineering and Information sciences University of Wollongong, Wollongong, NSW 2522 Australia. Ph: +61242213046 ; Fax: +61242213238

Email: indra@uow.edu.au 


\title{
Experimental Study to Examine the Role of Under Sleeper Pads for Improved Performance of Ballast under Cyclic Loading
}

Chamindi Jayasuriya ${ }^{1}$, Buddhima Indraratna ${ }^{2}$, FTSE, FASCE and Trung Ngoc $\mathrm{Ngo}^{3}, \mathrm{PhD}$, MIEAus

\begin{abstract}
The degradation and deformation of ballast critically affect the track geometry, safety, and passenger comfort. The increase in axle loads and train speed increases the stress applied on the ballast and exacerbates the rate of ballast degradation. This situation is more critical when tracks are built on stiff subgrades (e.g. bridges, tunnels and crossings), hence the use of energy absorbing (damping) layers in track substructure is a countermeasure to minimize track damage. In this study, a series of large-scale laboratory tests using the track process simulation testing apparatus (TPSA) is carried out to assess the performance of under sleeper pads (USP) to reduce ballast degradation and to decrease permanent deformation. When placed beneath the sleeper, the energy absorbing nature of USP reduces the energy transferred to the ballast and other substructure components. Subsequently, the ballast layer experiences less deformation and degradation. Innovative tactile surface sensors (matrixbased) are used to measure the pressure and contact area between sleeper and ballast. The measured data show that an increase in contact area between sleeper and ballast decreases the stress applied on ballast, and thus a reduction in ballast breakage and corresponding reduced ballast deformation can be achieved. Furthermore, the influence of the USP stiffness is examined and the measured data offer an insightful understanding of the role of USP for given track and loading conditions in terms of energy dissipation and reduced ballast deformation.
\end{abstract}

Keywords: Ballast; Under sleeper pads; Cyclic loading; Ballast breakage; Energy dissipation 


\section{Introduction}

Of the various modes of transportation currently available, the railway network is very important and as such has a significant impact on the productivity of mining and agriculture industry in Australia. Moreover, the rapid growth in population and urbanization, and increases in traffic congestion means that trains are now the most popular way to transport passengers and freight. However, this increasing demand for railways highlights the existing issues with conventional ballasted rail tracks and raises the apparent need for further improvements to cope with higher axle loads and high frequencies (Powrie et al. 2008). Ballast layer plays a vital role in transmitting and distributing induced train loads to underneath layers and also help to maintain railway geometry and dissipate a large percentage of the energy emanating from moving trains (Selig \& Waters 1994, Suiker et al. 2005). Li et al. (2015) found that track deterioration was faster and quickly becomes more critical for ballasted tracks built on stiff subgrades (e.g. concrete bridge decks, tunnels and crossings) where the damping capacity of the track cannot withstand the heavy cyclic loads. In heavy haul freight services, ballast aggregates subject to high stresses and experience irrecoverable (plastic) deformation due to particle breakage and subsequently affect the longevity and stability of tracks.

In recent years more attention has been given to minimise ballast degradation and to reduce the cost of track maintenance. Many reserchers have considered various methods to improve ballast performances such as ballast stabilization using geo grids (Hussaini et al. 2016; Indraratna et al. 2014; Liu et al. 2016; Ngo et al. 2016, 2017; Qian et al. 2015; Rahman et al. 2013), polymer reinforcement (D’Angelo et al. 2016; Kennedy et al. 2013; Woodward et al. 2014), fiber reinforcement (Ajayi et al. 2017) and mixing tyre derived aggregates with ballast (Chan \& Johan 2016; Esmaeili et al. 2017; Fathali et al. 2016; Sol-Sánchez et al. 2015) etc. 
The most recent trend is to use synthetic rubber pads placed underneath sleepers (under sleeper pad - USP) to enhance track performances (Indraratna et al. 2014; Insa et al. 2012; Kaewunruen 2010; Kaewunruen et al. 2018; Markine et al. 2011; Wan et al. 2016). Application of USP to mitigate vibration and noise generated by rolling stock has been attracted by past studies (Lakušić et al. 2010; Loy 2012; Müller 2008; Stahl 2005; Thompson \& Jones 2006). However, the application of USPs raises questions about their impact on long-term and overall track performance in both structural and geotechnical perspective. But, in many fields and laboratory studies have emphasised that the use of USP has given a positive result regarding reducing maintenance frequency and associated costs (Schilder 2013; Schneider et al. 2011).

Nimbalkar et al. (2012) investigated the performance of rubber mats under impact load and found that rubber mats decrease the impact-induced strains in the ballast by as much as $50 \%$. The inclusion of USP can reduce the stress transferred to the ballast by increasing the contact area between aggregate particles and concrete sleeper (Abadi et al. 2015; Li \& McDowell 2018). Differential settlements that stem from abrupt changes of track stiffness is another challenge in track design, and the USP can be utilised to prevent the unevenness stiffness and misalignment of tracks (Lakušić et al. 2010; Lundqvist \& Dahlberg 2005; Paixão et al. 2018). A recent study conducted by Navaratnarajah et al. (2018) showed that the inclusion of a rubber pad at the sleeper-ballast interface decreased the stresses transmitted to the underlying ballast and capping layers; resulting in reduced deformation and degradation of ballast aggregates. It is noted that only one type of rubber pad was tested in the above study. Moreover, to the knowledge of the authors, studies conducted to evaluate the performance of ballasted tracks with USP on stiff foundations (bridges, tunnels and crossings) rarely visible in literature. In addition, previous studies did not consider the influence of different stiffness 
of USP on the performance of ballast in terms of damping, energy dissipation and associated ballast breakage. Based on three different types of rubber sheets, this paper presents a more detailed experimental study on the role of under sleeper pad (USP) in improved performance of ballasted track built on a stiff foundation and to quantify the influence of USP stiffness on the load-deformation response of ballast.

\section{Experimental investigation}

\subsection{Large-scale track process simulation testing apparatus}

To investigate the effect of under sleeper pad (USP) and the influence of the pad stiffness on ballast, a series of large-scale tests using a track process simulation testing apparatus (TPSA) were conducted (Fig. 1a). The dimensions of the testing chamber are based on a unit cell of standard gauge Australian rail track. Sleepers are laid at a spacing of $600 \mathrm{~mm}$, so by applying symmetry around the centre line of the sleeper, the effective length of ballast per sleeper in a longitudinal direction at the sleeper-ballast interface is $600 \mathrm{~mm}$ (Biabani and Indraratna 2015). In a transverse direction, this dimension is based on the effective length of the sleeper that supports the load transferred by rolling stock. Jeffs and Tew (1991) proposed that the effective length $\left(l_{\mathrm{e}}\right)$ is equivalent to one-third of the total length of a sleeper, so since a standard Australian concrete sleeper is $2400 \mathrm{~mm}$ long, the effective length is $800 \mathrm{~mm}$.

The testing chamber is deep enough $(600 \mathrm{~mm})$ to accommodate an actual track substructure arrangement. This apparatus can simulate realistic track conditions because three independent principal stresses can be applied in three orthogonal directions. The walls of the testing chamber can move freely in lateral and longitudinal directions, so the required confinement (i.e. provided by the weight of the crib and shoulder ballast in a real rail track) can be applied through the hydraulic jacks attached to the walls (Fig. 1b). Each vertical wall can move $50 \mathrm{~mm}$ outwards to represent a maximum transverse strain of $12.5 \%$ under field conditions. 
Lateral displacement and pressures in a lateral direction (on each wall) are measured from the linear variable differential transformers (LVDT) and load cells attached to the hydraulic jacks on each wall. A cyclic load is then applied onto the rail by the servo-hydraulic actuator, as shown in Fig. 1c.

\subsection{Materials used for laboratory tests}

Fresh ballast consists of aggregates crushed from latite (volcanic) basalt, supplied by Bombo Quarry, south of Wollongong city. Ballast properties such as strength, mineralogy, flakiness etc. were analysed in the laboratory, and the particle size distribution was selected according to the Australian Standards (AS2758.7-2015). Ballast sample was washed and dried to assure the sample was free of dust, mud, and dirt, and then sieved before testing and mixed again to obtain the required gradation (Fig. 1d). A thin film of spray paint was used to colour-code the aggregates to differentiate the shoulder ballast from the ballast placed under the sleeper and to quantify particle breakage.

Three different types of under sleeper pads (Fig. 1e) were used in this experiment series. Mechanical properties of these pads are presented in Table 1. The pads were glued to the bottom surface of the concrete sleeper (790 mm long $\times 220 \mathrm{~mm}$ wide) according to the product manual.

\subsection{Cyclic loading characteristics}

The cyclic major principal stress $\sigma_{c y c}^{\prime}$ was applied to the rail in accordance with Fig. 1c, representing for 25 tonne axle load of coal trains. At the beginning, a monotonic load was applied until the applied stress reached the mean cyclic stress of, $\sigma_{c y c \text {,mean }}^{\prime}=130 \mathrm{kPa}$. The stress control load was then applied that consisted of the conditioning phase and the loading phase, and the amplitude $\left(A_{c y c}\right)$ of the cyclic load was equivalent to half the difference between the maximum and the minimum cyclic deviator stress $\left(A_{c y c}=\frac{1}{2}\left[\sigma_{c y c, \max }^{\prime}-\right.\right.$ 
$\left.\left.\sigma_{c y c, m i n}^{\prime}\right]\right)$. It is essential to have the conditioning phase prior to the loading phase to ensure that the sleeper is in contact with ballast to avoid damages to the actuator that can occur as a result of losing contact with the rail. During the conditioning phase, the cyclic load was applied at a relatively low frequency $(f=5 \mathrm{~Hz})$ up to $N=1000$ cycles and the actual loading was applied for the remaining cycles. The magnitudes of $\sigma_{c y c, \max }^{\prime}=230 \mathrm{kPa}$ and $\sigma_{c y c, \min }^{\prime}=30 \mathrm{kPa}$ were determined in accordance with Navaratnarajah and Indraratna (2017), and in relation to the field measurements conducted by Indraratna et al. (2010) for coal trains with 25 tonne axle load. The actual lateral confinement $\left(\sigma^{\prime}{ }_{3}=10 \mathrm{kPa}\right)$ generated as a result of the weight of shoulder ballast was applied on the ballast sample through the lateral walls of the TPSA. For a long straight rail track, the longitudinal displacement is usually negligible, so the walls of the testing chamber were locked to restrict movement in a longitudinal direction, thus making $\varepsilon_{2}=0$. For a given train speed, 150 the loading frequency was calculated by considering the distance between the last wheel of the 151 front bogie, the first wheel of the next bogie. For the laboratory tests conducted in this study, 152 the appropriate loading frequencies were selected as $\mathrm{f}=15,20$, and $25 \mathrm{~Hz}$, to represent a train 153 travelling at $97 \mathrm{~km} / \mathrm{h}, 130 \mathrm{~km} / \mathrm{h}$, and $160 \mathrm{~km} / \mathrm{h}$, respectively (Indraratna \& Ngo 2018). Number of total load cycles applied on the ballast can be determined by:

$C_{m}=\frac{10^{6}}{A_{t} \times N_{a}}$

where, $C_{m}=$ number of cycles per million gross tons (MGT); $A_{t}=$ axle load in tons; and $N_{\mathrm{a}}=$ number of axles/load cycle. Considering 50MGT of annual traffic tonnage and four axles per load cycle, an axle load of 25tonne gives 500,000 load cycles. Therefore, in this set of experiments, the cyclic load is applied up to 500,000 cycles. 


\subsection{Laboratory testing procedure}

To simulate a ballasted track built on stiff subgrades such as bridges, tunnels, and road crossings, a $150 \mathrm{~mm}$ thick concrete deck was placed at the bottom of the testing chamber, as shown in Fig. 2a. Ballast aggregates were sieved, washed, dried, mixed to the required gradation and then placed inside the testing chamber in three layers (100 mm thick), as shown in Figs. 2b-d. Each layer was compacted with a vibratory compactor and a rubber pad that attaches to the vibratory plate to avoid damaging the aggregates. To represent a field condition, the unit weight ballast specimen were kept at $15.4 \mathrm{kN} / \mathrm{m}^{3}$. The sleeper and the rail assembly were placed on top of a $300 \mathrm{~mm}$ thick layer of compacted ballast (with or without USP, depending on the test), as shown in Fig. 2e.

Instruments such as potentiometers, LVDT, load cells and matrix-based tactile surface sensors (MBTSS) were used to measure and record data during these tests. The pressure and contact area at the ballast/sleeper interface were measured by the MBTSS placed underneath the sleeper (Fig. 2f). The sensors was calibrated using linear multi point calibration method which facilitate by the software used to control the sensor. The calibration technique was provided by the sensor manufacture. The sensor was place on thin ballast layer and set of known static loads have applied on sensor using flat steel plate. The calibration data can be saved separately and can import to the raw data file and the calibration can be done either before or after the test as it is independent process. The sensor used for the experiments have a sensing area of $500 \times 200 \mathrm{~mm}$ (area of the matrix) and 14.8 sensel per square inch. A controlling unit was connected to the ballast sample to record and transfer data from the sensors through data loggers (Fig. $2 \mathrm{~g}$ ). The shoulder ballast was then placed on top of the load bearing ballast in a layer up to $150 \mathrm{~mm}$ high. Cyclic loading was applied onto the rail using a dynamic actuator (100mm diameter), as shown in Fig. 2h. Eight tests were carried out 
with and without sleeper pads glued underneath the concrete sleeper; where three different types of sleeper pads (Fig. 1e) were used. The laboratory program is summarised in Table 2.

\section{Results and discussion}

\subsection{Influence of frequencies on ballast deformation}

\subsubsection{Vertical and lateral deformation}

The long-term accumulation of ballast deformation is a major concern in track design, because, the deterioration of track geometry adversely affects the passenger comfort and safety. For that purpose, the load-deformation response of the ballast (with and without USP) under different loading frequencies was evaluated. Six tests were conducted, and for each test, the accumulated permanent deformations of ballast were measured at the end of 100 , 500, 1000, 5000, 10000, 20000, 50000, 100000, 200000, 300000, 400000, 500000 load cycles. The corresponding plastic strains were then calculated in the vertical $\left(\varepsilon_{1}\right)$ and lateral $\left(\varepsilon_{3}\right)$ directions. These measurements were obtained from the potentiometers fixed to the sleeper, and from the settlement plates placed on top of the load bearing ballast layer.

As shown in Figs. 3a-b, an increase in train speed (increased frequency) results in increased vertical and lateral displacements (i.e. increased corresponding strains, $\varepsilon_{1}$ and $\varepsilon_{3}$ ). As the train speed increases, more of the kinetic energy is transmitted to the track foundation. Consequentlly, ballast breakage along with particle rearrangement and densification causeses a significant increase of irrecoverable (plastic) deformation. The use of USP contributes to a considerable reduction in the permanent deformation of ballast. Figures $3 \mathrm{c}-\mathrm{d}$ demonstrate that the USP can reduce the permanent vertical displacement, $S_{v}$ from $16-47 \%$ and decrease lateral plastic displacement, $S_{L}$ from $21-55 \%$.

Ballast deforms rapidly up to 10,000 cycles, and significant strain accumulation can then be observed. After 10,000 cycles, the rate of deformation gradually decreases, and the ballast 
becomes more stable after about 100,000 load cycles. The rapid increase of deformation in the initial load cycles is probably due to the rearrangement of aggregates and the breakage of angular projections of flaky aggregates. During this period, the granular layer becomes denser as the grains compact and the deformation gradually increases as ballast approaches its optimum density, beyond which the aggregates are crushed or fractured. The rate of strain accumulation diminishes as the rate of particle breakage and cyclic densification decrease (Figs. 3a-b). This observation is in agreement with previous studies conducted by SolSánchez et al. (2014) and Navaratnarajah et al. (2018) using USP for ballasted tracks placed on soft subgrade.

\subsubsection{Volumetric and shear strains}

The vertical strain $\left(\varepsilon_{1}\right)$ of the ballast layer was calculated based on the differences between settlement at the sleeper and ballast interface, as measured by the settlement pegs. The lateral strain $\left(\varepsilon_{3}\right)$ parallel to the sleeper was calculated using the lateral displacement of the vertical walls, as measured by the potentiometers. The volumetric strain $\left(\varepsilon_{v o l}\right)$ and shear strain $\left(\varepsilon_{s}\right)$ can be determined as:

$\varepsilon_{v o l}=\varepsilon_{1}+\varepsilon_{2}+\varepsilon_{3}$

$\varepsilon_{s}=\frac{\sqrt{2}}{3}\left\{\sqrt{\left(\varepsilon_{1}-\varepsilon_{2}\right)^{2}+\left(\varepsilon_{2}-\varepsilon_{3}\right)^{2}+\left(\varepsilon_{1}-\varepsilon_{3}\right)^{2}}\right\}$

Considering the plane strain condition movement in the longitudinal direction is restricted and thus $\varepsilon_{2}=0$, therefore:

$\varepsilon_{v o l}=\varepsilon_{1}+\varepsilon_{3}$ 
$\varepsilon_{s}=\frac{\sqrt{2}}{3}\left\{\sqrt{\left(\varepsilon_{1}\right)^{2}+\left(\varepsilon_{3}\right)^{2}+\left(\varepsilon_{1}-\varepsilon_{3}\right)^{2}}\right\}$

The variation of volumetric and shear strains of ballast with and without the inclusion of USP subjects to different frequencies is presented in Figs. 4a-b. It is seen that while the increase in loading frequency causes a significant increase in strain accumulation, the presence of USP helps to decrease volumetric and shear strains considerably. Figs. 4c-d demonstrate that the USP helps to reduce the volumetric strain about $15-45 \%$ and decreases the shear strain around 16-48\%. Rapid increases in volumetric and shear strains are observed within first 10,000 cycles, and the rate of strain accumulation gradually decreases and attained a relatively stable condition after 100,000 cycles.

\subsubsection{Resilient modulus of ballast}

Resilient modulus of ballast $\left(M_{r}\right)$ is determined as the ratio between $\Delta \sigma_{c y c}$ (the difference between the maximum cyclic deviator stress, $\sigma_{c y c, \max }^{\prime}$, and the minimum cyclic deviator stress, $\left.\sigma_{c y c, \text { min }}^{\prime}\right)$ and recoverable axial strain during unloading, $\varepsilon_{1 r} ;\left(M_{r}=\Delta \sigma_{c y c} / \varepsilon_{1 r}\right)$. Figure 5 shows the variation of resilient modulus with the number of cycles. Rapid increase of $M_{r}$ is measured up to 100,000 cycles, and afterwards, its rate of increase becomes marginal. Rapid densification of ballast during the initial load cycles causes an increase in stiffness, and as a result, a rapid increase in $M_{r}$ at the beginning is observed. After 100,000 cycles, the ballast is in a more stable condition and this contributes to the reduction of the rate of increase of $M_{r}$.

When the USP is used, the recoverable axial strain $\varepsilon_{1 r}$ is generally higher compared to the case without the USP. This partly attributed to the elastic response and high compressibility of the USP), resulting in a reduction in the value of $M_{r}$. Figure 5 shows that the inclusion of the USP decreases the resilient modulus of ballast by around 15\%. The additional resiliency provided by the USP causes the recoverable elastic strain to proliferate under the same load 
(compared to the case of without USP), given the compressibility of rubber. Qi et al. (2017) and Signes et al. (2015) have studied the effect of rubber crumbs on the resilient modulus of sub-ballast, and they have reported that the increase in rubber percentage can decrease the resilient modulus of the granular layer.

\subsubsection{Energy absorbing capacity and damping ratio}

The kinetic energy generated by the cyclic loading is transmitted to the ballast layer, and the ballast can then distribute the energy to the underlying subgrade (Esveld 2001). Subjected to cyclic loading, ballast exhibits hysteresis response and the energy dissipated during loading/unloading $\left(E_{d}\right)$ can be calculated according to ASTM D3999 (2003). As explained in Figure 6a, the energy dissipated per load cycle is proportional to the area of the loop $\left(A_{L}\right)$, as represented by the energy per unit volume per loading-unloading cycle $\left(E_{d}=A_{L}\right)$. The damping ratio $(D)$ is proportional to the ratio of energy dissipated and stored during the loading-unloading cycle, as given by:

$D=\frac{A_{L}}{4 \pi A_{S}}$

where $A_{L}$ is the area of the hysteresis loop; $A_{s}$ is the area of the shaded right triangle (Fig. 6a).

The variations of damping ratio and energy dissipation per load cycle of ballast assembly with and without USP are illustrated in Figs. 6b-c, respectively. Here, the USP significantly increases the damping ratio $(D)$ and energy dissipation $\left(E_{d}\right)$. Higher energy dissipation occurs at initial load cycles due to the rearrangement of particles and breakage. As the ballast grains move towards a more stable condition, (significantly diminished volumetric strain), the energy dissipated at each load cycle decreases, and the variation among subsequent load cycles becomes insignificant. Additionally, the energy transmitted to the ballast increases 
with the increased loading frequency (i.e. faster trains generate more kinetic energy), accompanied by a greater intensity of plastic deformation and particle breakage.

The total energy dissipates per load cycle $\left(E_{d}\right)$ is a combination of energy absorbed by the sleeper pad $\left(E_{p a d}\right)$, energy spent on breakage $\left(E_{B}\right)$ and the rearrangement $\left(E_{S}\right)$ of the ballast particles, defined as:

$E_{d}=E_{P a d}+E_{S}+E_{B}$

Navaratnarajah and Indraratna (2017) defined the energy absorbed by rearrangement of particles $\left(E_{s}\right)$ as a function of deviator stress $\left(q_{d}\right)$ and the total shear stress $\left(\varepsilon_{s}\right)$ and the energy dissipated through particle breakage $\left(E_{B}\right)$ as a function of axle load $(\kappa)$ and ballast breakage index (BBI). Cansidering those relationships the Eq.7 can be rewritten as:

$$
E_{d}=E_{P a d}+a\left(q_{d} \varepsilon_{s}\right)+b(\kappa \times B B I)^{c}
$$

The USP is an elastic medium, and its energy absorbing capacity depends on the area $(A)$, thickness $(T)$, deformation $(x)$ and elastic modulus $(E)$ of the sleeper pad. $N$ is the number cycles, and the total energy dissipate per load cycle is calculated by:

$$
E_{d}=\frac{1}{2}\left(\frac{A E}{T}\right) x^{2} \times N+a\left(q_{d} \varepsilon_{s}\right)+b(\kappa \times B B I)^{c}
$$

where, $a, b$ and $c$ are empirical parameters, and $\kappa$ is a factor normalized to the axle load.

Equation 9 can now be used to estimate the energy dissipation per load cycle of ballast assembly subject to cyclic loading. 


\subsubsection{Stress distribution at the ballast-sleeper interface}

The interface between sleeper and ballast is considered to have relatively high stress due to the low effective contact area between the aggregates and a hard concrete surface that can cause more damage to the ballast aggregates at the interface (Abadi et al. 2015). Past studies have used metal pressure plates to measure the stresses (Navaratnarajah et al. 2018), and the main disadvantages of these pressure plates is the incapability of measuring pressure distribution under the whole sleeper due to limited sensing area, and they provided additional stiffness due to the thick rigid plate $(10 \mathrm{~mm}$ thick). To overcome these drawbacks, a matrixbased tactile surface sensor (MBTSS) has been used in this study to measure accurate pressure and contact area at the sleeper-ballast interface. This thin film pressure sensor is $0.1 \mathrm{~mm}$ thick and consists of two thin flexible polyester sheets with conductive silver ink printed on it as rows and columns (Fig. 2f). Pressure sensitive semiconducting material is applied to the inner surface of the silver rows and columns, and the two sheets are sandwiched together to form a grid (matrix). When a load is applied on the sensor, the upper sheet and the lower sheet will touch each other, and the electrical resistance generated in the contact point of rows and columns is inversely proportional to the applied normal force.

Figure 7 presents the contact area and pressure at the sleeper-ballast interface measured under 25tonne axle load with and without USP. It can be seen that the USP can improve the contact area significantly up to approximately 2.5 times (i.e. contact area: $47,180 \mathrm{~mm}^{2}$ with USP compared to $18,820 \mathrm{~mm}^{2}$ without USP). The contact area between sleeper and ballast is measured to be only $18 \%$ when the USP is not used, while this value increases up to $50 \%$ with the presence of USP. When the ballast is directly in contact with sleeper, the stress concentration becomes very high (i.e. causing ballast breakage) where the presence of highstress concentration points is clearly visible. Aggregates penetrate in to the USP causing an increase in the contact area. Thus a significant reduction in the contact stress can be observed. 
Additionally, the inclusion of USP improves the uniformity of the stress distribution and contact area at the sleeper-ballast interface.

\subsection{Influence of the USP stiffness}

Additional two tests were conducted with varied USP stiffness (i.e. $0.1 \mathrm{~N} / \mathrm{mm}^{3}$ and 0.15 $\mathrm{N} / \mathrm{mm}^{3}$ ) to investigate the role of USP stiffness on the load-deformation response of ballast. Figs. 8a-b shows the variation of vertical and lateral displacements with changing pad stiffness. The measured data shows that the presence of USP reduces the deformation of ballast (plastic strains), and the stiffer rubber pads (i.e. higher rigidity) perform better than flexible pads (i.e. more compressibility). As shown in Figures 8c-d, use of stiffer pad (i.e. stiffness $=0.22 \mathrm{~N} / \mathrm{mm}^{3}$ ) has been able to reduce vertical and lateral displacements of ballast up to $45 \%$ and $48 \%$, respectively.

The volumetric and shear strains responses are analysed with varying USP stiffness. As presented in Figs. 9a-b, regardless of USP stiffness, a greater accumulation of volumetric and shear strains can be seen for initial 10,000 load cycles, and after about 100,000 cycles, the rate of strain accumulation decreases. The volumetric and shear strain accumulation has been decreased by the inclusion of USP. The USP decreases the volumetric strains of ballast from 22-45\% (Fig. 9c) and reduces the shear strain from 20-48\% (Fig. 9d) for the USP's stiffness ranging from $0.1-0.22 \mathrm{~N} / \mathrm{mm}^{3}$, respectively.

Figure 10a shows the variations of the resilient modulus of ballast, $M_{r}$ with varying stiffness of USP. It is measured that the smaller stiffness of USP used, the lower resilient modulus of ballast is measured. Therefore, the suitable stiffness of under sleeper pad should be selected carefully considering the adverse effect on reduced resilient modulus of ballast. Figure $10 \mathrm{~b}$ shows energy dissipations per load cycle with different types of USP stiffness. Compared to the case without USP, the energy dissipation increases with the presence of USP; and the 
smaller stiffness of USP (i.e. reduced rigidity) the higher energy dissipation is measured. With reduction of pad stiffness the area of the hysteresis loop has increased and indicates a higher energy dissipation with ballast and USP. With the soft pad highest energy dissipation is observed and this is due to high recoverable strain and higher ballast degradation as shown in figure $10 \mathrm{~b}$.

Laboratory test data demonstrates that the beneficial effect of USP towards improved track performance is diminished with reduced stiffness (increased compressibility) of the USP. Based on the measured data, an empirical equation is proposed to predict vertical, lateral strains and ballast breakage, given by:

$$
\varepsilon=\alpha \times k^{\beta}
$$

Where, $\varepsilon$ is strain (\%), $k$ is USP stiffness, and $\alpha$ and $\beta$ are empirical parameters as summarised in Figure 11. As shown in Figure 11, USP with the highest stiffness $(0.22$ $\mathrm{N} / \mathrm{mm}^{3}$ ) gives the lowest plastic deformation strain at the end of 500,000 load cycles, and this is due to reduced ballast breakage.

\subsection{Quantifying ballast breakage}

As Figure 12 illustrates, aggregates covered with a thin film of spray paint helps to clearly identify the breakage before and after the test. There are three types of ballast degradation are observed, namely: abrasion, attrition, and fracturing. Ballast breakage is quantified using the ballast breakage index (BBI) introduced earlier by Indraratna et al. (2005) as shown in Figure 13a. The $\mathrm{BBI}$ is given by the relationship: $B B I=A /(A+B)$, where, $A$ is shift in the particle size distribution (PSD) curve after the load application and $B$ is potential breakage or the area between the arbitrary boundary of maximum breakage and the final PSD curve. Figure 13b shows that the presence of USP helps to reduce the ballast breakage significantly (i.e. BBI 
decreases from $51 \%$ to $60 \%$ for given frequencies of $\mathrm{f}=15-25 \mathrm{~Hz}$ ). The increase of the contact area between sleeper and ballast helps to reduce the pressure developed on ballast, and therefore, a reduction in ballast degradation can be observed. As shown in Figure 13c, increasing stiffness of USP (increased rigidity) results in decreased ballast breakage. In addition, an increase in frequency (i.e. train speed) causes more damage to the ballast, and gradual increase of the BBI can be observed with the increasing loading frequency for both with and without USP.

\section{Conclusions}

This paper presented the results from large-scale laboratory tests using the Track Process Simulation Testing Apparatus (TPSA) to assess the influence of under sleeper pads (USP) on the deformation and degradation of ballast placed on stiff foundations (concrete bridge decks, tunnels and crossings) subjected to varying cyclic loading frequencies, $f=15,20$ and $25 \mathrm{~Hz}$. Three different types of sleeper (tie) pads (varying stiffness) were placed underneath a concrete sleeper, and all tests were subjected to cyclic train loading of $\sigma_{c y c, \max }^{\prime}=230 \mathrm{kPa}$, representing heavy haul trains having a minimum of 25 tonne axle load. The following conclusions can be drawn:

- The laboratory results confirmed that the introduction of USP contributed to a significant reduction of permanent deformation of ballast. The inclusion of USP decreased the vertical and lateral displacements of ballast by approximately $16-50 \%$, and the volumetric and shear strains by $15-48 \%$. The USP could also decrease the degradation of ballast (breakage) by about 51-60\% .

- The stiffness of the USP also affected the improved performance of ballast. The smaller the stiffness of USP (i.e. reduced rigidity) the higher the measured total 
energy dissipation. The presence of USP could decrease the resilient modulus of ballast, thus increasing the total energy dissipation. Measured test data indicated that the beneficial effect of USP was diminished with reduced stiffness (i.e. increased compressibility) where the stiffest pad (i.e. stiffness $=0.22 \mathrm{~N} / \mathrm{mm}^{3}$ ) was able to reduce vertical and lateral displacements of ballast by $45 \%$ and $55 \%$, respectively. The USP also decreases the volumetric strain of ballast by $15-45 \%$ and reduces the shear strain by $16-48 \%$ for stiffness ranging from 0.1 to $0.22 \mathrm{~N} / \mathrm{mm} 3$, respectively.

- The increase of loading frequency, $f$ causes an increase in the deformation and degradation of ballast. Under a given frequency, ballast exhibited significant deformation during initial load cycles, and this tended to ease after 10,000 cycles, and the ballast layer became more stable after almost 100,000 load cycles. When the frequency increased from 15 to $25 \mathrm{~Hz}$ (equivalent to train speed of $97-160 \mathrm{~km} / \mathrm{h}$ ), the vertical and lateral displacements of ballast increased considerably due to more kinetic energy being transferred to ballast aggregates.

- Using matrix-based tactile surface sensors (MBTSS), the pressure and contact area at the sleeper-ballast interface could be measured accurately. The contact area between the sleeper and ballast was measured to be only $18 \%$ when the USP was not used, while this value increased up to 50\% with the presence of USP. In addition, the use of USP improved the uniformity of the stress distribution at the sleeper-ballast interface, thus resulting in a reduced number of stress concentration points beneath the sleeper.

In summary, placing rubber mats beneath concrete sleepers as under sleeper pads (USP) is a favourable solution to reduce the deformation and degradation of ballast, and thereby minimizing the track maintenance costs, enabling heavy haul trains to move faster while carrying greater loads. 


\section{Acknowledgements}

The authors wish to acknowledge the Australian Research Council (ARC) and Industry partners for providing support through the ARC Industrial Transformation Training Centre for Advanced Technologies in Rail Track Infrastructure (ITTC-Rail). The authors greatly appreciate the financial support from the Rail Manufacturing Cooperative Research Centre (funded jointly by participating rail organisations and the Australian Federal Government's Business Cooperative Research Centres Program) through Project R2.5.1: Performance of recycled rubber inclusions for improved stability of railway. Assistance provided by A/Prof Cholachat Rujikiatkamjorn and Dr Sinniah Navaratnarajah are gratefully acknowledged. The continuous support provided by technical officers Alan Grant, Cameron Neilson and Ritchie McLean during laboratory work is highly appreciated. 


\section{References}

Abadi, T, Le Pen, L, Zervos, A \& Powrie, W 2015, 'Measuring the area and number of ballast particle contacts at sleeper/ballast and ballast/subgrade interfaces', The International Journal of Railway Technology, vol. 4, no. 2, pp. 45-72.

Ajayi, O, Le Pen, L, Zervos, A \& Powrie, W 2017, 'Scaling relationships for strip fibrereinforced aggregates', Canadian Geotechnical Journal, vol. 54, no. 5, pp. 710-9.

AS2758.7 2015, Aggregates and rock for engineering purposes, Part 7: Railway ballast, Standards Australia, Sydney, New South Wales, Australia.

ASTMD3999 2003, Standard Test Methods for the Determination of the Modulus and Damping Properties of Soils Using the Cyclic Triaxial Apparatus, ASTM International, West Conshohocken,USA.

Biabani, MM \& Indraratna, B 2015, 'An evaluation of the interface behaviour of rail subballast stabilised with geogrids and geomembranes', Geotextiles and Geomembranes, vol. 43, no. 3, pp. 240-9.

Chan, C-M \& Johan, S 2016, 'Shear resistance improvement of oil-contaminated ballast layer with rubber shred inclusions', International Journal og GEOMATE, vol. 11, no. 27, pp. 2723-9.

D’Angelo, G, Thom, N \& Presti, DL 2016, 'Bitumen stabilized ballast: A potential solution for railway track-bed', Construction and Building Materials, vol. 124, pp. 118-26.

Esmaeili, M, Aela, P \& Hosseini, A 2017, 'Experimental assessment of cyclic behavior of sand-fouled ballast mixed with tire derived aggregates', Soil Dynamics and Earthquake Engineering, vol. 98, pp. 1-11.

Esveld, C 2001, Modern railway track, Second Edition edn, The Netherlands : MRT Productions.

Fathali, M, Nejad, FM \& Esmaeili, M 2016, 'Influence of tire-derived aggregates on the properties of railway ballast material', Journal of Materials in Civil Engineering, vol. 29, no. 1, p. 04016177.

Hussaini, SKK, Indraratna, B \& Vinod, JS 2016, 'A laboratory investigation to assess the functioning of railway ballast with and without geogrids', Transportation Geotechnics, vol. 6, pp. 45-54.

Indraratna, B, Lackenby, J \& Christie, D 2005, 'Effect of confining pressure on the degradation of ballast under cyclic loading', Géotechnique, vol. 55, no. 4, pp. 325-8.

Indraratna, B \& Ngo, T 2018, Ballast Railroad Design: SMART-UOW Approach, CRC Press, Taylor \& Francis Group.

Indraratna, B, Nimbalkar, S, Christie, D, Rujikiatkamjorn, C \& Vinod, J 2010, 'Field assessment of the performance of a ballasted rail track with and without geosynthetics', Journal of geotechnical and geoenvironmental engineering, vol. 136, no. 7, pp. 907-17.

Indraratna, B, Nimbalkar, S \& Rujikiatkamjorn, C 2014, 'From theory to practice in track geomechanics-Australian perspective for synthetic inclusions', Transportation Geotechnics, vol. 1, no. 4, pp. 171-87. 
Insa, R, Salvador, P, Inarejos, J \& Roda, A 2012, 'Analysis of the influence of under sleeper pads on the railway vehicle/track dynamic interaction in transition zones', Journal of Rail and Rapid Transit, vol. 226, no. 4, pp. 409-20.

Jeffs, T \& Tew, G 1991, 'A review of track design procedures: sleepers and ballast, Vol. 2', Railways of Australia BHP Research, Melbourne Laboratories, Melbourne, Australia.

Kaewunruen, S 2010, 'Effectiveness of using elastomeric pads to mitigate impact vibration at an urban turnout crossing', in W Schröder/Aachen, BJ Boersma/Delft, K Fujii/Kanagawa, W Haase/München, MA Leschziner/London, J Periaux/Paris, S Pirozzoli/Rome, A Rizzi/Stockholm, B Roux/Marseille \& Y Shokin/Novosibirsk (eds), 10th International Workshop on Railway Noise, Nagahama, Japan, pp. 357-65.

Kaewunruen, S, Ngamkhanong, C, Papaelias, M \& Roberts, C 2018, 'Wet/dry influence on behaviors of closed-cell polymeric cross-linked foams under static, dynamic and impact loads', Construction and Building Materials, vol. 187, pp. 1092-102.

Kennedy, J, Woodward, P, Medero, G \& Banimahd, M 2013, 'Reducing railway track settlement using three-dimensional polyurethane polymer reinforcement of the ballast', Construction and Building Materials, vol. 44, pp. 615-25.

Lackenby, J, Indraratna, B, McDowell, G \& Christie, D 2007, 'Effect of confining pressure on ballast degradation and deformation under cyclic triaxial loading', Géotechnique, vol. 57, no. 6, pp. 527-36.

Lakušić, S, Ahac, M \& Haladin, I 2010, 'Experimental investigation of railway track with under sleeper pad', in 10th Slovenian road and transportation congress.

Li, D, Hyslip, J, Sussmann, T \& Chrismer, S 2015, Railway geotechnics, CRC Press, Taylor \& Francis Group, Boca Raton, FL New York, USA.

Li, D, Otter, D \& Carr, G 2010, 'Railway bridge approaches under heavy axle load traffic: problems, causes, and remedies', Proceedings of the Institution of Mechanical Engineers, Part F (Journal of Rail and Rapid Transit), vol. 224, no. F5, pp. 383-90.

Li, H \& McDowell, GR 2018, 'Discrete element modelling of under sleeper pads using a box test', Granular Matter, vol. 20, no. 2, p. 26.

Liu, S, Huang, H, Qiu, T \& Kwon, J 2016, 'Effect of geogrid on railroad ballast particle movement', Transportation Geotechnics, vol. 9, pp. 110-22.

Loy, H 2012, 'Mitigating vibration using under-sleeper pads', Railway Gazette International, vol. 168 , no. 4.

Lundqvist, A \& Dahlberg, T 2005, 'Railway track stiffness variation-consequences and countermeasures', in 19th IAVSD Symposium of Dynamics of Vehicles on Roads and Tracks, Milano, August 29-Seprember 2, 2005.

Markine, V, Steenbergen, M \& Shevtsov, I 2011, 'Combatting RCF on switch points by tuning elastic track properties', Wear, vol. 271, no. 1-2, pp. 158-67.

Müller, R 2008, 'Mitigation measures for open lines against vibration and ground-borne noise: a Swiss overview', in Noise and vibration mitigation for rail transportation systems, Springer, pp. 264-70.

Ngo, NT, Indraratna, B \& Rujikiatkamjorn, C 2016, 'Modelling geogrid-reinforced railway ballast using the discrete element method', Transportation Geotechnics, vol. 8, pp. 86-102. 
Ngo, NT, Indraratna, B \& Rujikiatkamjorn, C 2017, 'Stabilization of track substructure with geo-inclusions-experimental evidence and DEM simulation', International Journal of Rail Transportation, vol. 5, no. 2, pp. 63-86.

Navaratnarajah, SK \& Indraratna, B 2017, 'Use of Rubber Mats to Improve the Deformation and Degradation Behavior of Rail Ballast under Cyclic Loading', Journal of geotechnical and geoenvironmental engineering, vol. 143, no. 6, p. 04017015.

Navaratnarajah, SK, Indraratna, B \& Ngoc Trung, N 2018, 'Influence of Under Sleeper Pads on Ballast Behavior Under Cyclic Loading: Experimental and Numerical Studies', Journal of geotechnical and geoenvironmental engineering, vol. 144, no. 9, pp. 04018068 1-16.

Nimbalkar, S, Indraratna, B, Dash, SK \& Christie, D 2012, 'Improved performance of railway ballast under impact loads using shock mats', Journal of geotechnical and geoenvironmental engineering, vol. 138, no. 3, pp. 281-94.

Paixão, A, Varandas, JN, Fortunato, E \& Calçada, R 2018, 'Numerical simulations to improve the use of under sleeper pads at transition zones to railway bridges', Engineering Structures, vol. 164, pp. 169-82.

Powrie, W, Priest, J \& Clayton, C 2008, 'Recent research on railway track sub-base behaviour', in Advances in transportation geotechnics: proceedings of the 1st international conference on transportation geotechnics, London, UK, pp. 37-46.

Qi, Y, Indraratna, B, Heitor, A \& Vinod, JS 2017, 'Effect of Rubber Crumbs on the Cyclic Behavior of Steel Furnace Slag and Coal Wash Mixtures', Journal of geotechnical and geoenvironmental engineering, vol. 144, no. 2, p. 04017107.

Qian, Y, Mishra, D, Tutumluer, E \& Kazmee, HA 2015, 'Characterization of geogrid reinforced ballast behavior at different levels of degradation through triaxial shear strength test and discrete element modeling', Geotextiles and Geomembranes, vol. 43, no. 5, pp. 393-402.

Rahman, M, Arulrajah, A, Piratheepan, J, Bo, M \& Imteaz, M 2013, 'Resilient modulus and permanent deformation responses of geogrid-reinforced construction and demolition materials', Journal of Materials in Civil Engineering, vol. 26, no. 3, pp. 512-9.

Schilder, R 2013, 'USP (Under Sleeper Pads): a contribution to save money in track maintenance', in AusRAIL PLUS 2013, Driving the Costs out of Rail, 26-28 November 2013, Canberra, ACT, Australia.

Schneider, P, Bolmsvik, R \& Nielsen, JC 2011, 'In situ performance of a ballasted railway track with under sleeper pads', Proceedings of the Institution of Mechanical Engineers, Part F: Journal of Rail and Rapid Transit, vol. 225, no. 3, pp. 299-309.

Selig, ET \& Waters, JM 1994, Track geotechnology and substructure management, Thomas Telford.

Signes, CH, Fernández, PM, Perallón, EM \& Franco, RI 2015, 'Characterisation of an unbound granular mixture with waste tyre rubber for subballast layers', Materials and Structures, vol. 48, no. 12, pp. 3847-61.

Sol-Sánchez, M, Moreno-Navarro, F \& Rubio-Gámez, MC 2014, 'Viability of using end-oflife tire pads as under sleeper pads in railway', Construction and Building Materials, vol. 64, pp. 150-6. 
Sol-Sánchez, M, Thom, N, Moreno-Navarro, F, Rubio-Gámez, M \& Airey, G 2015, 'A study into the use of crumb rubber in railway ballast', Construction and Building Materials, vol. 75, pp. 19-24.

Stahl, W 2005, 'Improvement of ballastless tracks using sleeper pads-investigations and experiences in Germany', in 7th International Conference on the Bearing Capacity of Roads, Railways and Airfields.

Suiker, A.S.J., Selig, E.T. and Frenkel, R. (2005). "Static and cyclic triaxial testing of ballast and subballast." Journal of Geotechnical and Geoenvironmental Engineering, ASCE 131(6), pp: 771-782.

Thompson, D \& Jones, C 2006, 'Noise and vibration from railway vehicles', in S Iwnicki (ed.), Handbook of Railway Vehicle Dynamics., Chemical Rubber Company Press, London, UK, pp. 279-325.

Wan, C, Markine, V \& Shevtsov, I 2016, 'Optimisation of the elastic track properties of turnout crossings', Proceedings of the Institution of Mechanical Engineers, Part F: Journal of Rail and Rapid Transit, vol. 230, no. 2, pp. 360.

Woodward, P, Kennedy, J, Laghrouche, O, Connolly, D \& Medero, G 2014, 'Study of Railway Track Stiffness Modification by Polyurethane Reinforcement of the Ballast', Transportation Geotechnics, vol. 1, no. 4, pp. 214-24. 
Table 1: Mechanical properties of under sleeper pad (USP) used in laboratory

\begin{tabular}{|c|c|c|c|}
\hline Material & & : Polyureth & olymer \\
\hline Dimensic & f the sleeper pad & :200 mm x & $\mathrm{nm}$ \\
\hline $\begin{array}{l}\text { Tear st } \\
\text { between }\end{array}$ & $\begin{array}{l}\text { gth of the co } \\
\text { USP and concrete }\end{array}$ & ion $: 0.5 \mathrm{~N} / \mathrm{mm}^{2}$ & \\
\hline USP No & Thickness (mm) & Weight $\left(\mathrm{kg} / \mathrm{m}^{2}\right)$ & $\begin{array}{l}\text { Static } \\
\left(\mathrm{N} / \mathrm{mm}^{3}\right)\end{array}$ \\
\hline 1 & 10 & 4.2 & 0.22 \\
\hline 2 & 10 & 4.2 & 0.15 \\
\hline 3 & 10 & 5.5 & 0.10 \\
\hline
\end{tabular}

Table 2: Laboratory experiment programme

Test series 1: Varying frequency (Axle load 25 tonne)

\begin{tabular}{|llll|}
\hline Test No & Frequency, $f(\mathrm{~Hz})$ & USP included & $\begin{array}{l}\text { Properties of USP } \\
\text { (Stiffness and Thickness) }\end{array}$ \\
\hline 1 & 15 & No & - \\
2 & 15 & Yes & $0.22 \mathrm{~N} / \mathrm{mm}^{3}, 10 \mathrm{~mm}$ \\
3 & 20 & No & - \\
4 & 20 & Yes & $0.22 \mathrm{~N} / \mathrm{mm}^{3}, 10 \mathrm{~mm}$ \\
5 & 25 & No & - \\
6 & 25 & Yes & $0.22 \mathrm{~N} / \mathrm{mm}^{3}, 10 \mathrm{~mm}$ \\
\hline Test series 2: Varying USP stiffness (Axle load 25 tonne) & \\
\hline Test No & Frequency, $f(\mathrm{~Hz})$ & USP included & $\begin{array}{l}\text { Properties } \\
(\text { Stiffness and Thickness })\end{array}$ \\
\hline 1 & 15 & No & - \\
2 & 15 & Yes & $0.22 \mathrm{~N} / \mathrm{mm}^{3}, 10 \mathrm{~mm}$ \\
7 & Yes & $0.15 \mathrm{~N} / \mathrm{mm}^{3}, 10 \mathrm{~mm}$ \\
8 & 15 & Yes & $0.10 \mathrm{~N} / \mathrm{mm}^{3}, 10 \mathrm{~mm}$ \\
\hline
\end{tabular}



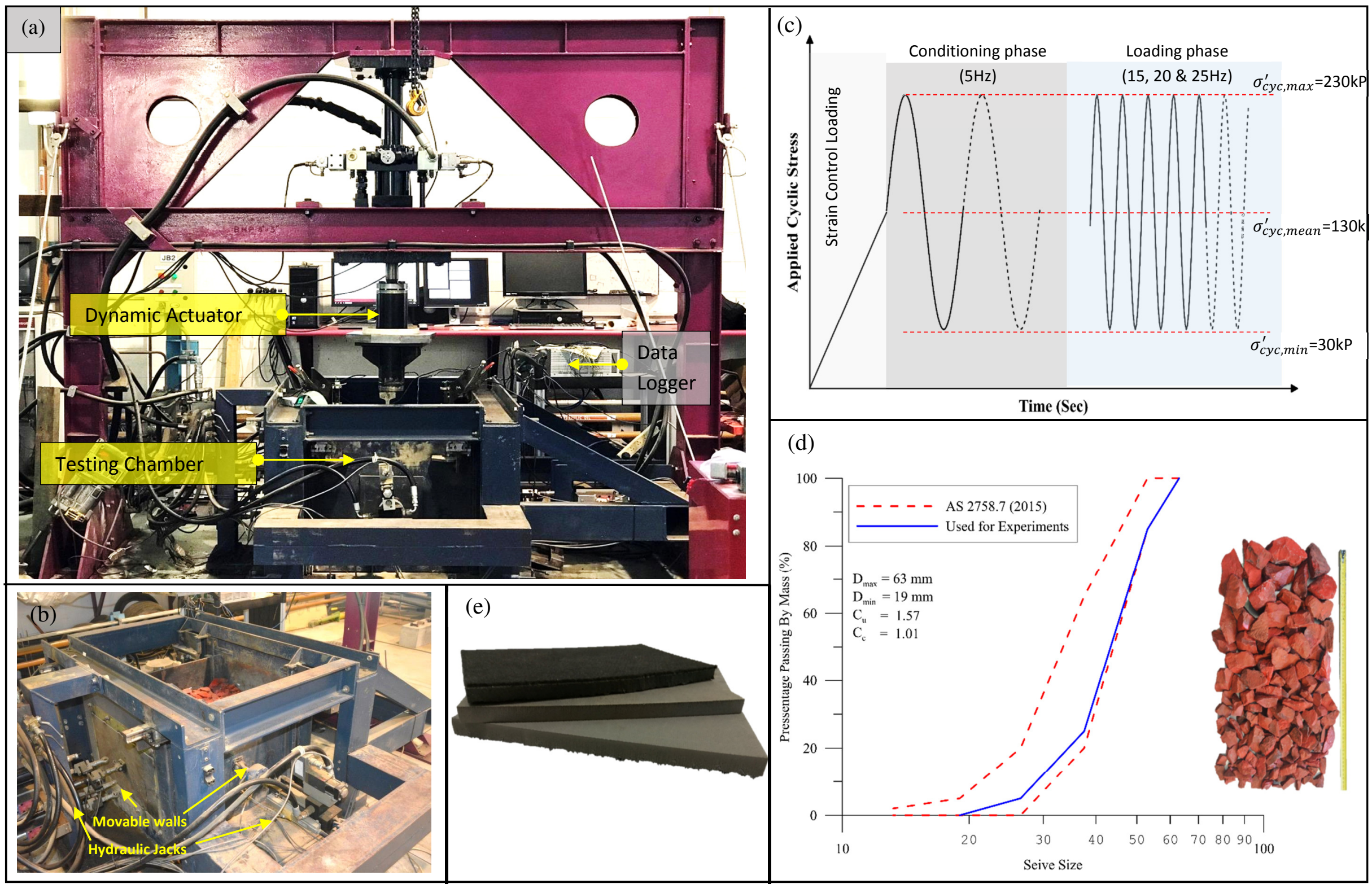

Figure 1: (a) Large scale track process simulation testing apparatus (TPSA); (b) Testing chamber; (c) Applied cyclic load (d) PSD curve of 25 tested ballast; (e) Under sleeper pads (USP) 


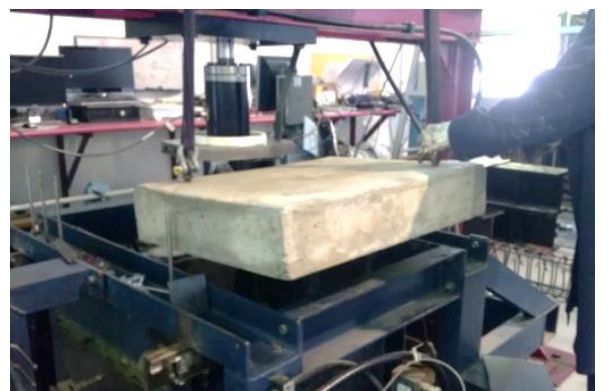

(a)

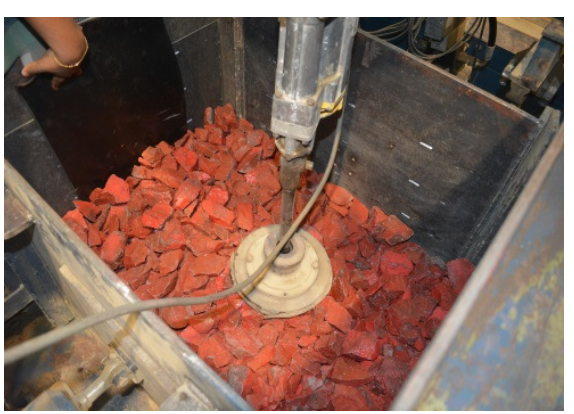

(d)

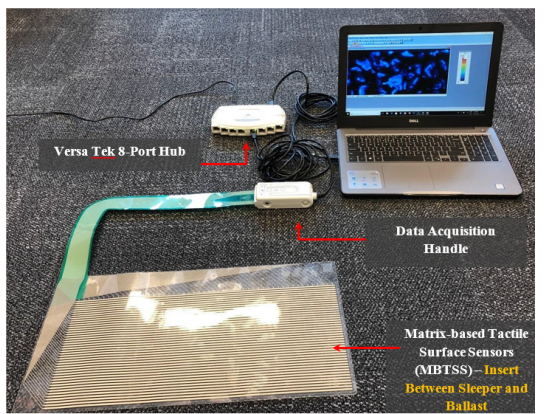

(f)

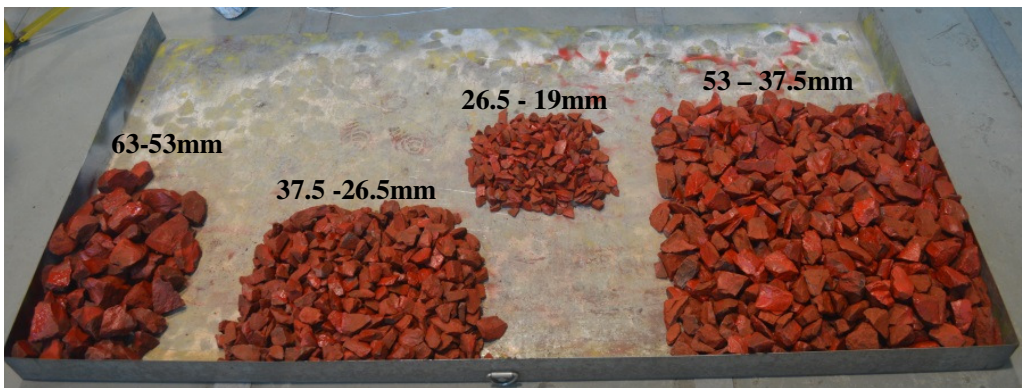

(b)

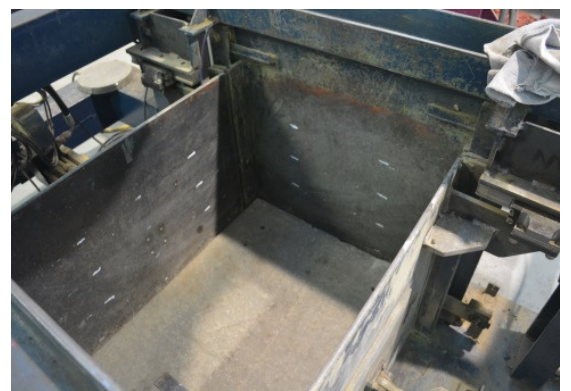

(c)

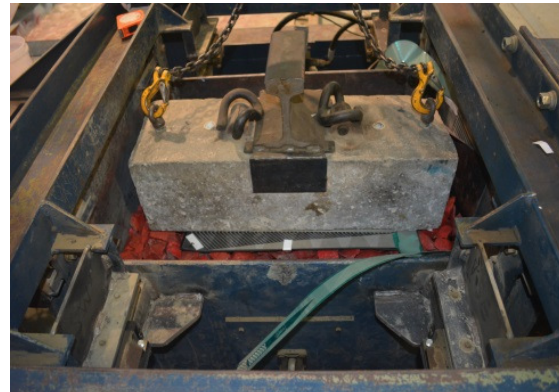

(e)

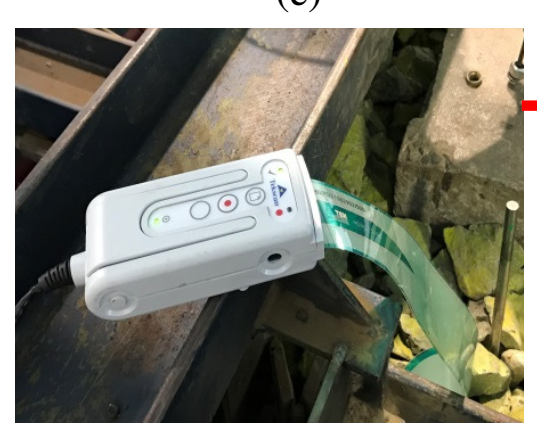

(g)

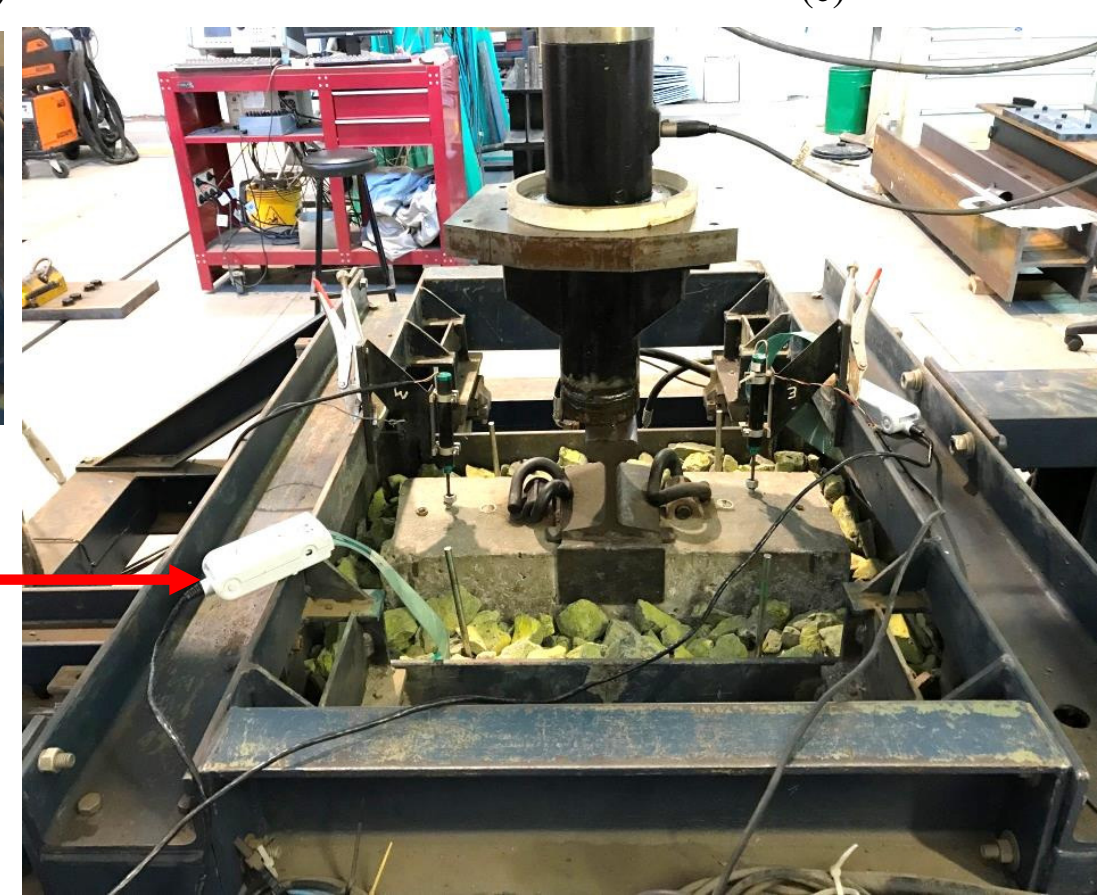

(h)

Figure 2: (a) Installing concrete deck; (b) Fresh ballast prepared for the experiment; (c) bottom of the testing chamber; (d) compacting ballast; (e) Placing concrete sleeper and rail; (f) Data acquisition and MBTS sensor controlling unit; (g) Data acquisition handle; (h) Final arrangement of testing chamber 
(a)

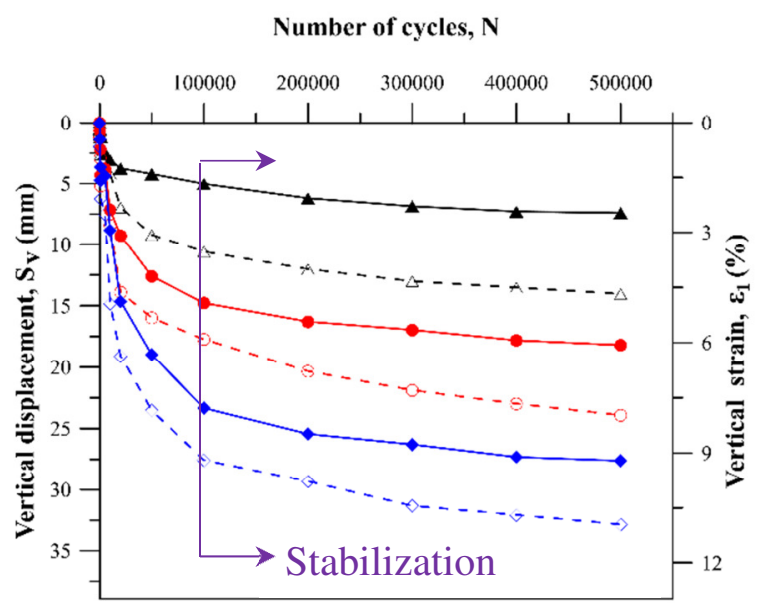

(b)

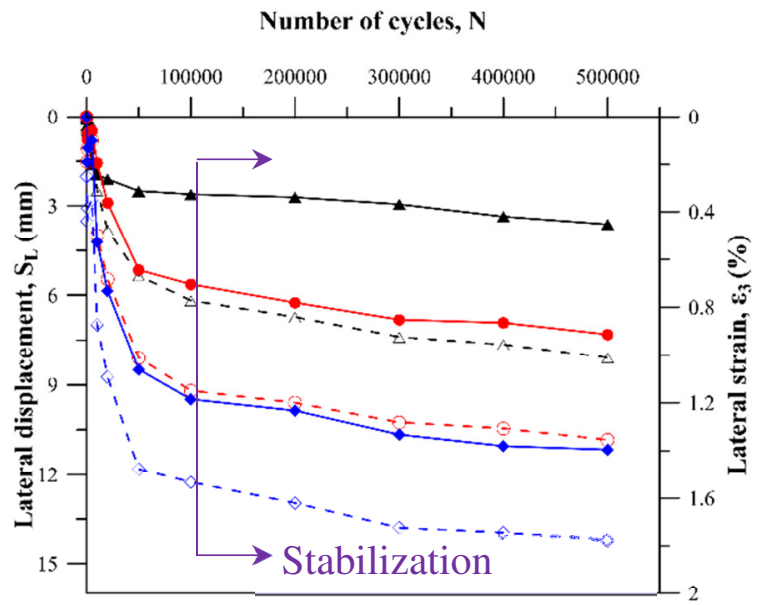

(c)

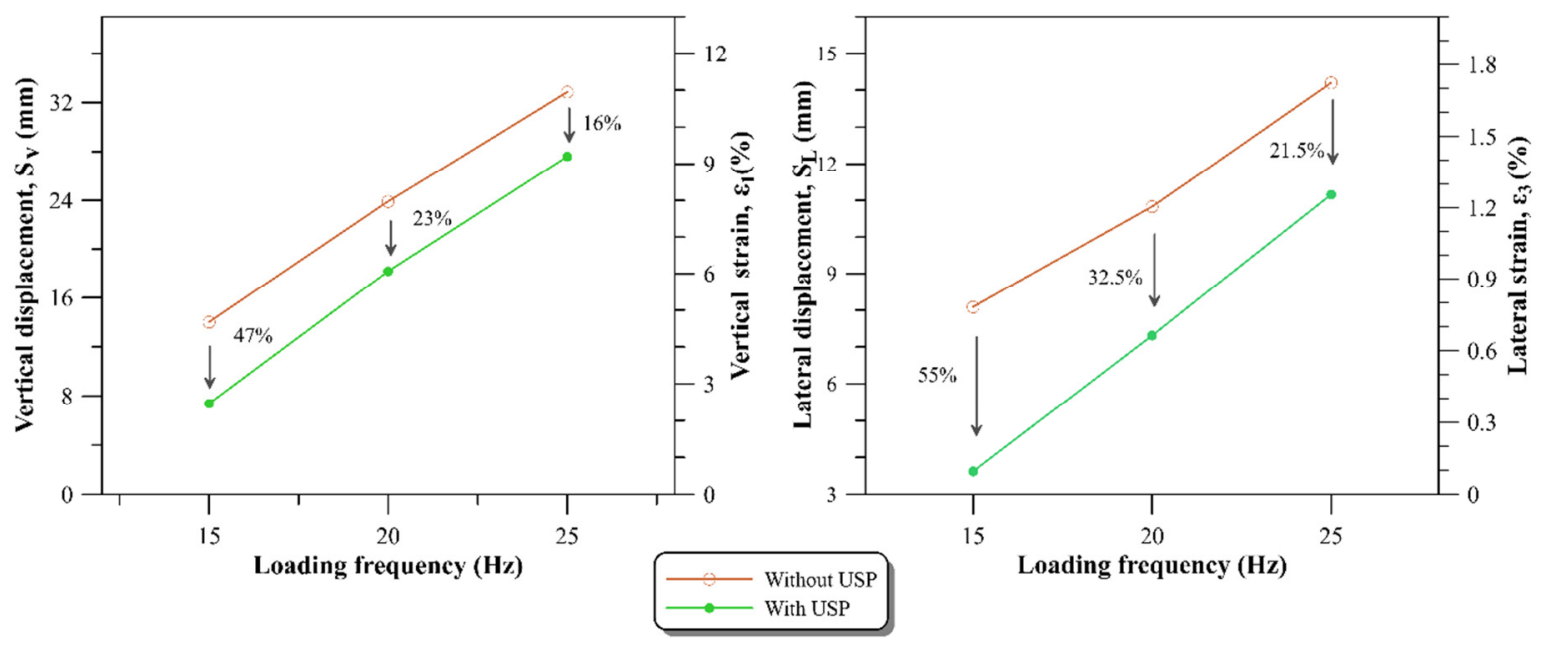

Figure 3: Effect of the USP on: (a) Vertical displacement; (b) Lateral displacement; (c)

Reduction of vertical displacement; and (d) Reduction of lateral displacement 
(a)

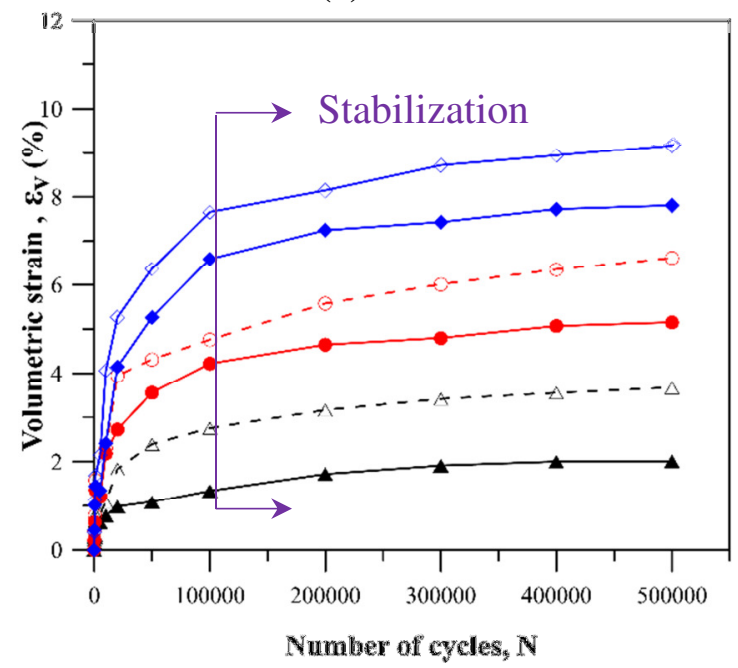

(c)

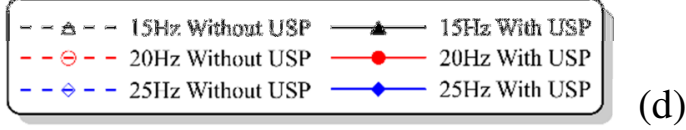

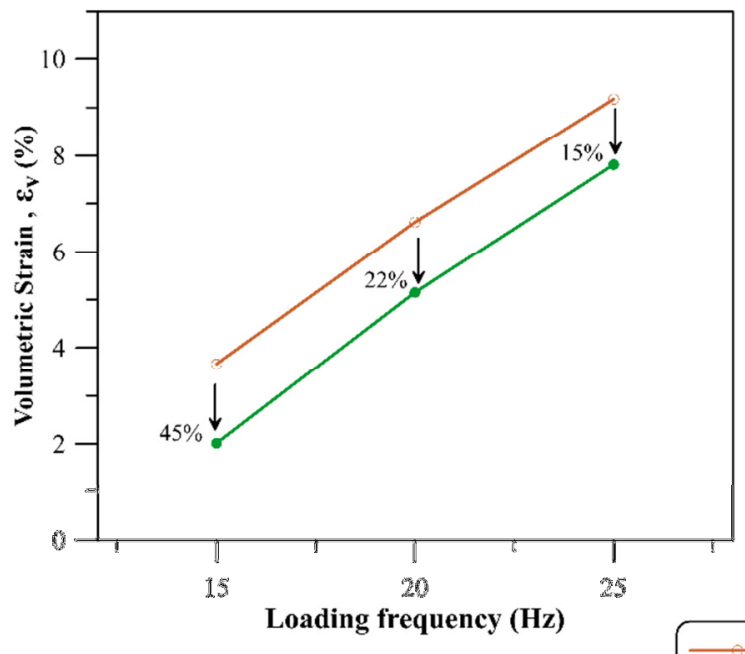

Loading frequency $(\mathrm{Hz})$ (b)

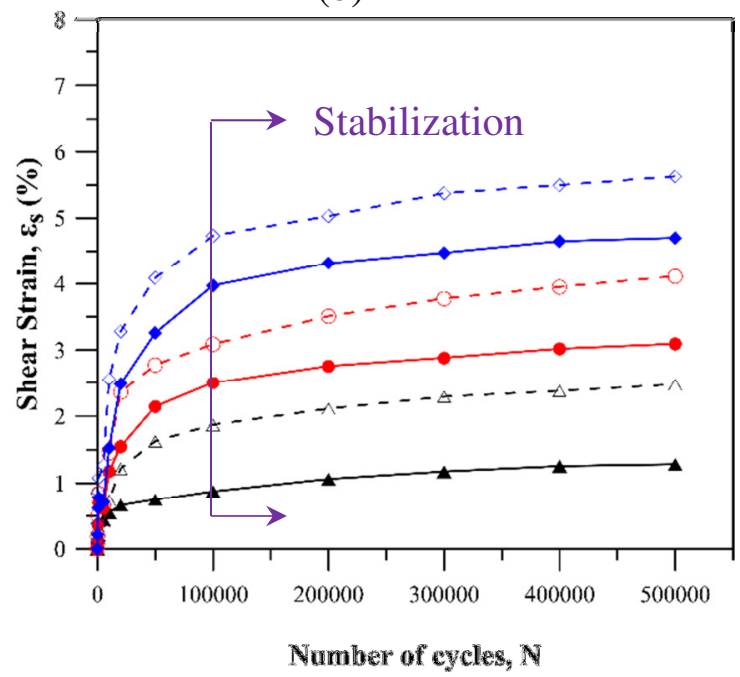

(d)

Figure 4: Effect of the USP on: (a) Volumetric strain; (b) Shear strain; (c)

Reduction of volumetric strain; and (d) Reduction of shear strain 


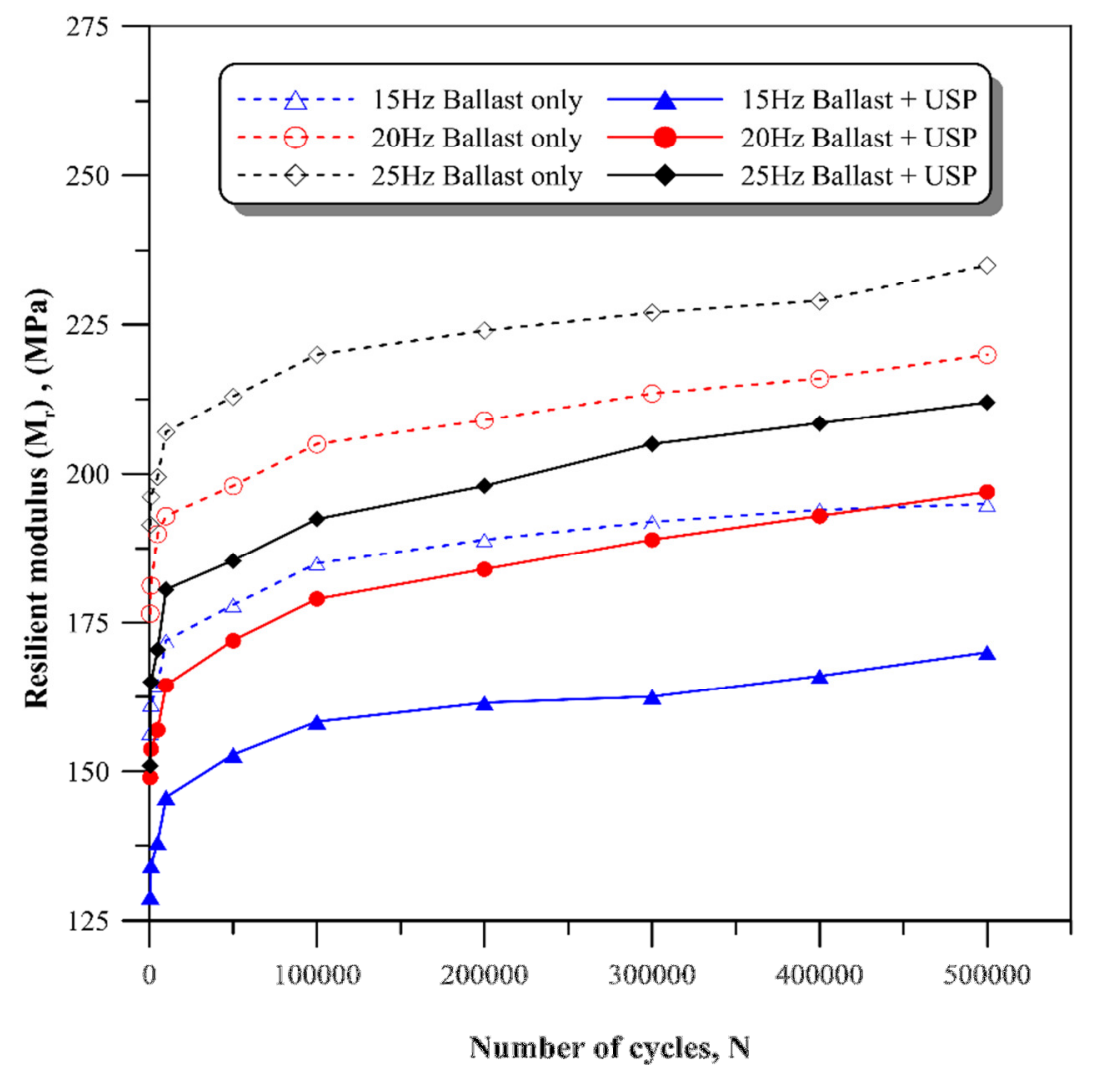

Figure 5: Variation of resilient modulus, $M_{r}$ of ballast with and without the USP 
(a)

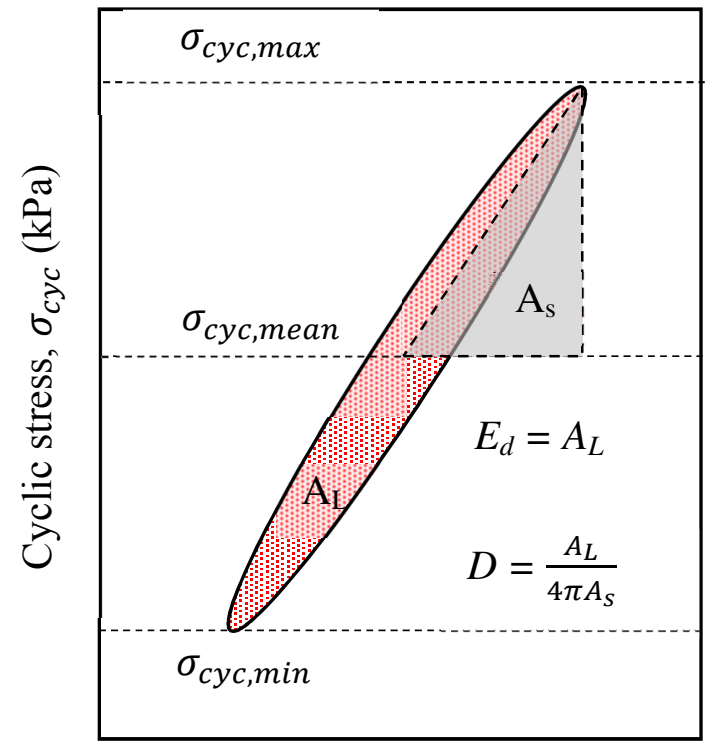

Strain, $\varepsilon$

(b)

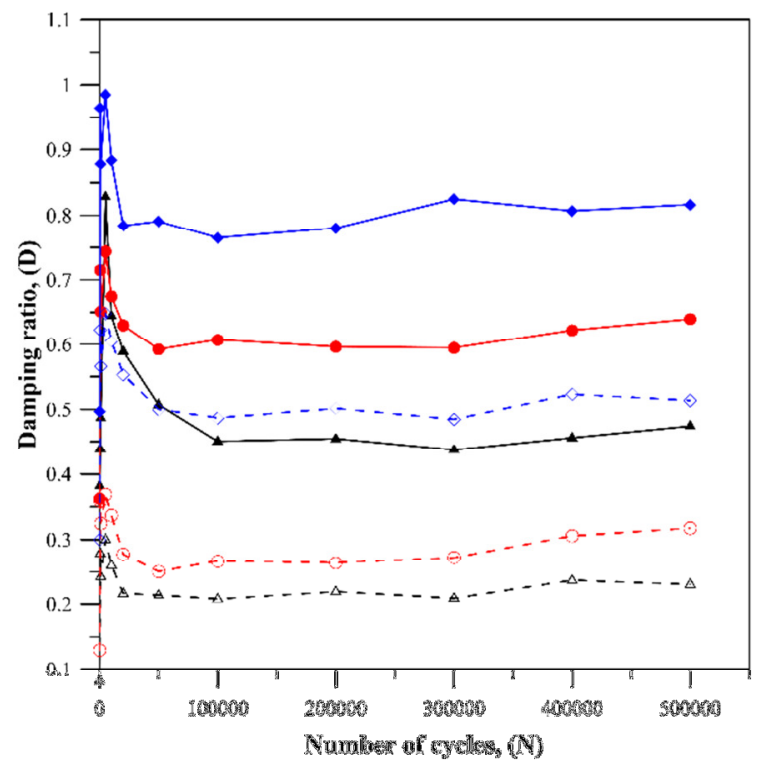

(c)

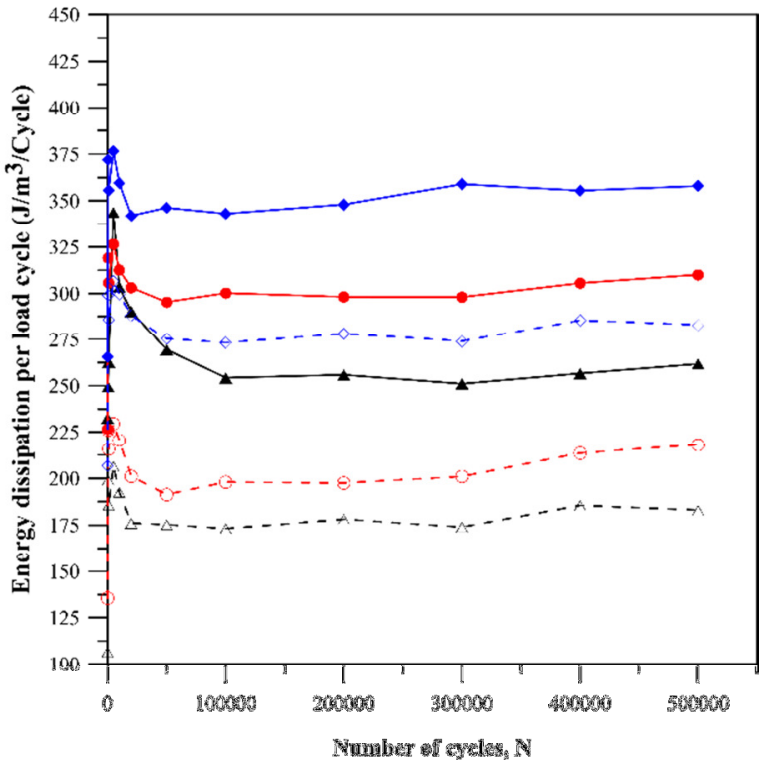

Figure 6: (a) Schematic of a typical hysteresis loop and method of calculating damping ratio, $D$;

(b) Variation of damping ratio; and (c) Variation of energy dissipation, $E_{d}$ 
(a) Total sensing area: $99675 \mathrm{~mm}^{2}$; Contact area: $18820 \mathrm{~mm}^{2}$; Applied load: $40 \mathrm{kN}$
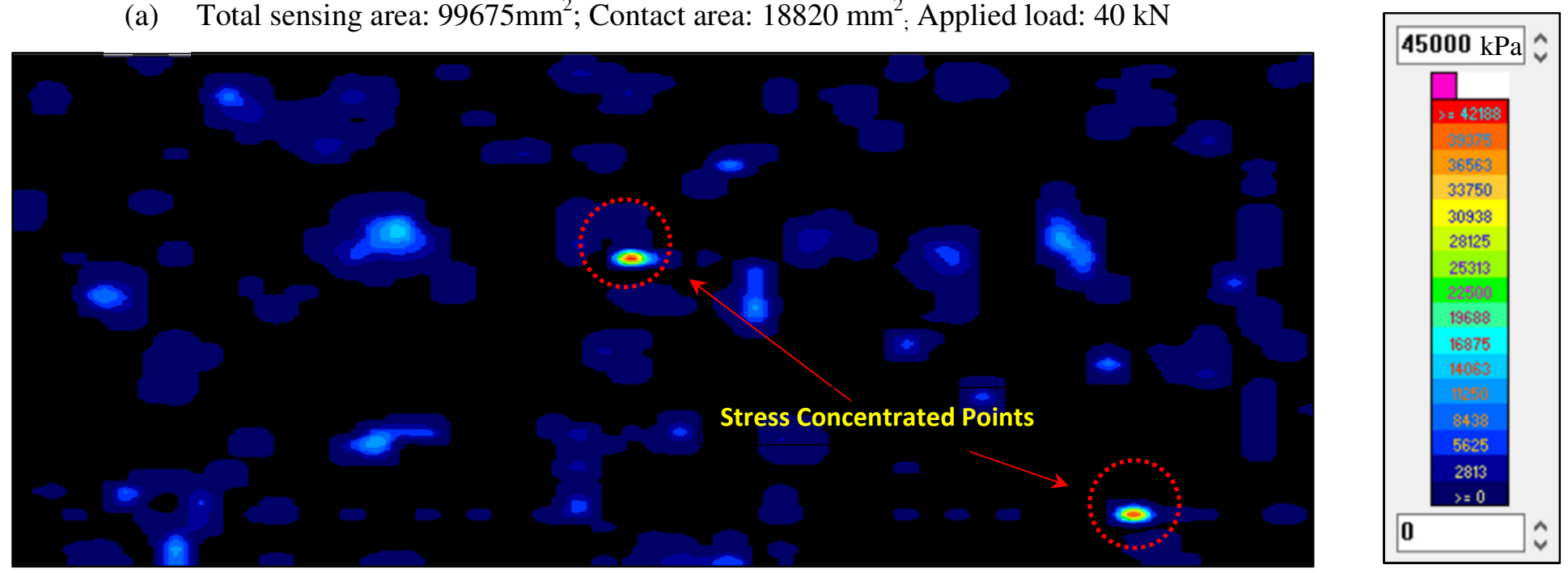

(b) Total sensing area: $99675 \mathrm{~mm}^{2}$; Contact area: $47180 \mathrm{~mm}^{2 \text {; }}$ Applied load: $40 \mathrm{kN}$
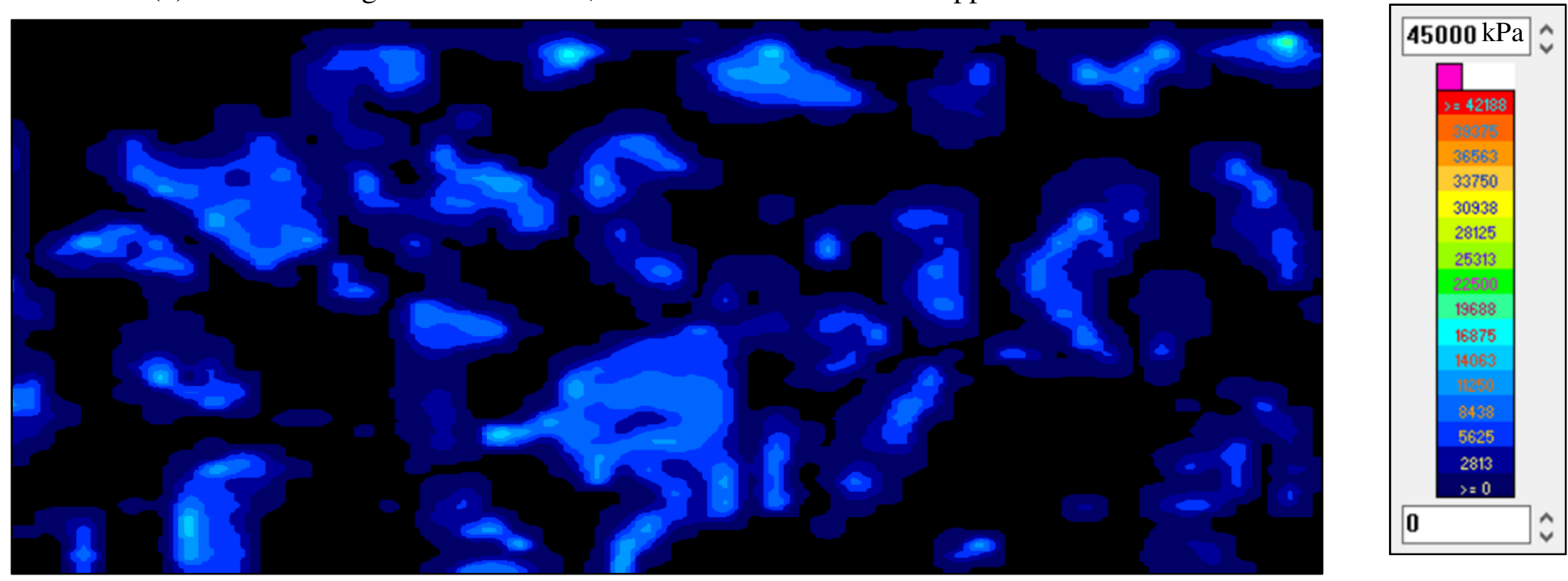

Figure 7: Stress distribution at the ballast /sleeper interface: (a) without USP (b) with USP 
(a)

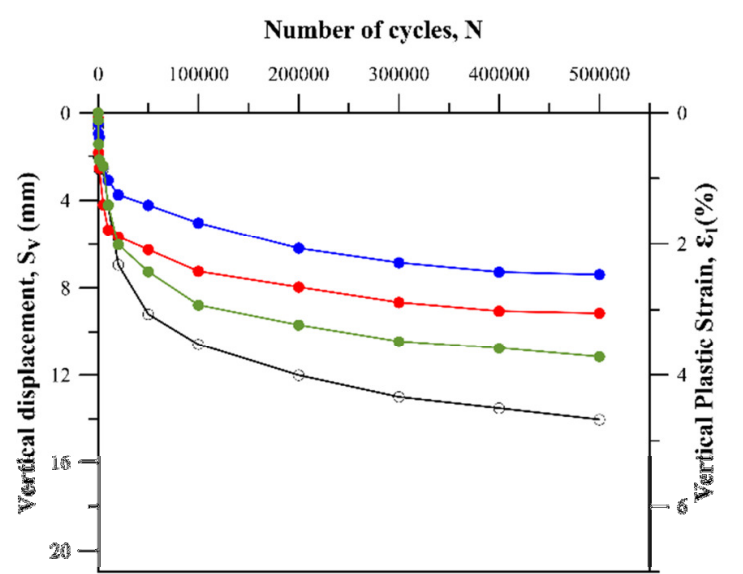

(b)

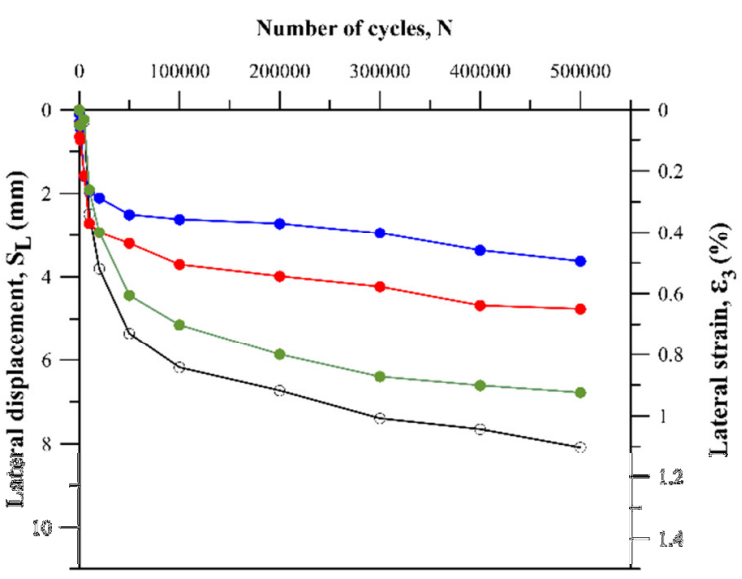

(d)
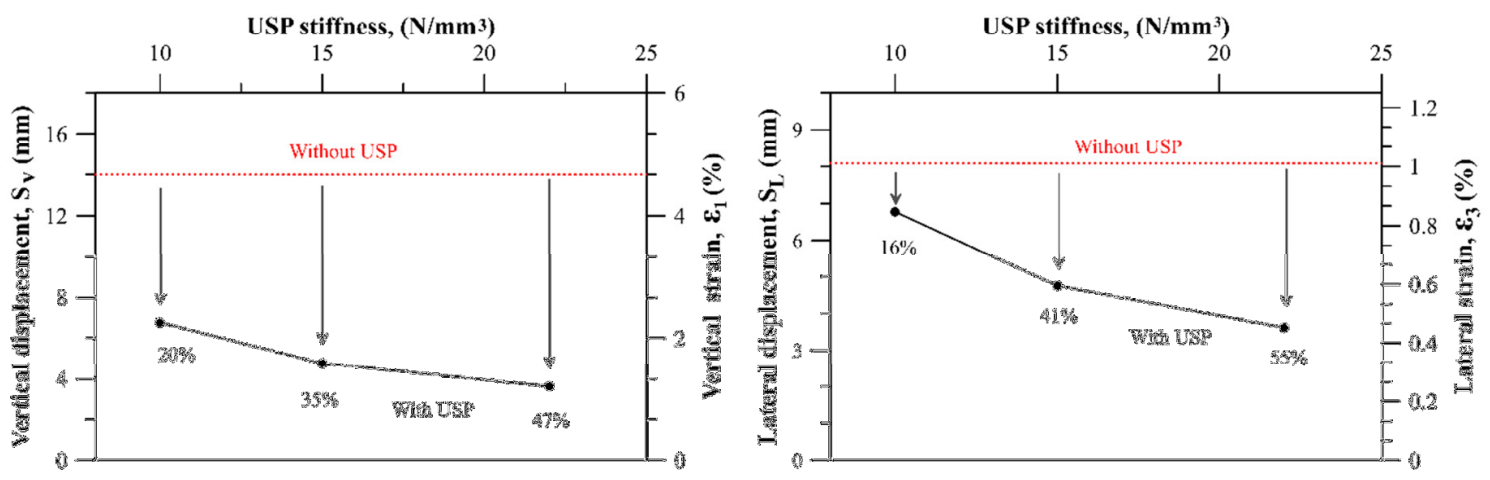

Figure 8: Influence of USP stiffness on: (a) Vertical displacement; (b) Lateral displacement;

(c) Reduction of vertical displacement; and (d) Reduction of lateral displacement 
(a)
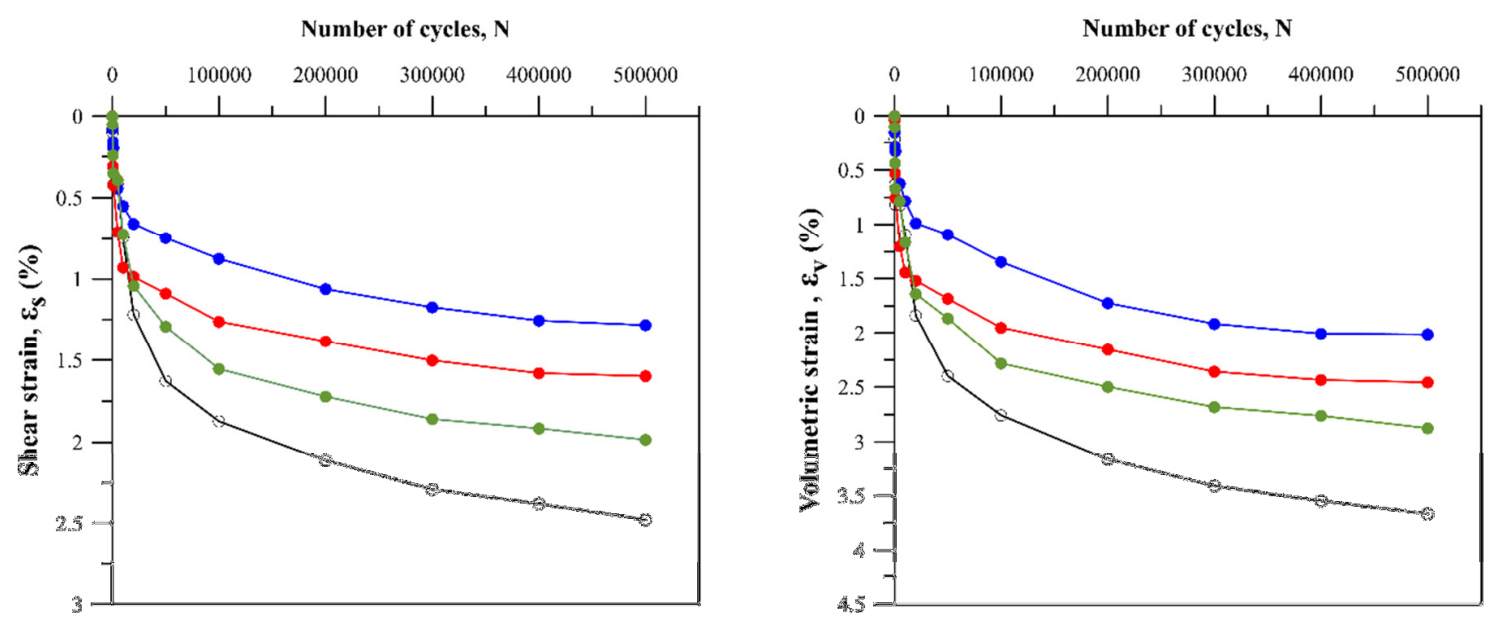

(c) \begin{tabular}{l}
$\square-$ Without USP \\
$\square$ With USP - Stiffness $0.22 \mathrm{~N} / \mathrm{mm}^{3}$ \\
$\square$ With USP - Stiffness $0.15{\mathrm{~N} / \mathrm{mm}^{3}}^{3}$ \\
\hline- With USP - Stiffness $0.10 \mathrm{~N} / \mathrm{mm}^{3}$
\end{tabular}

(d)
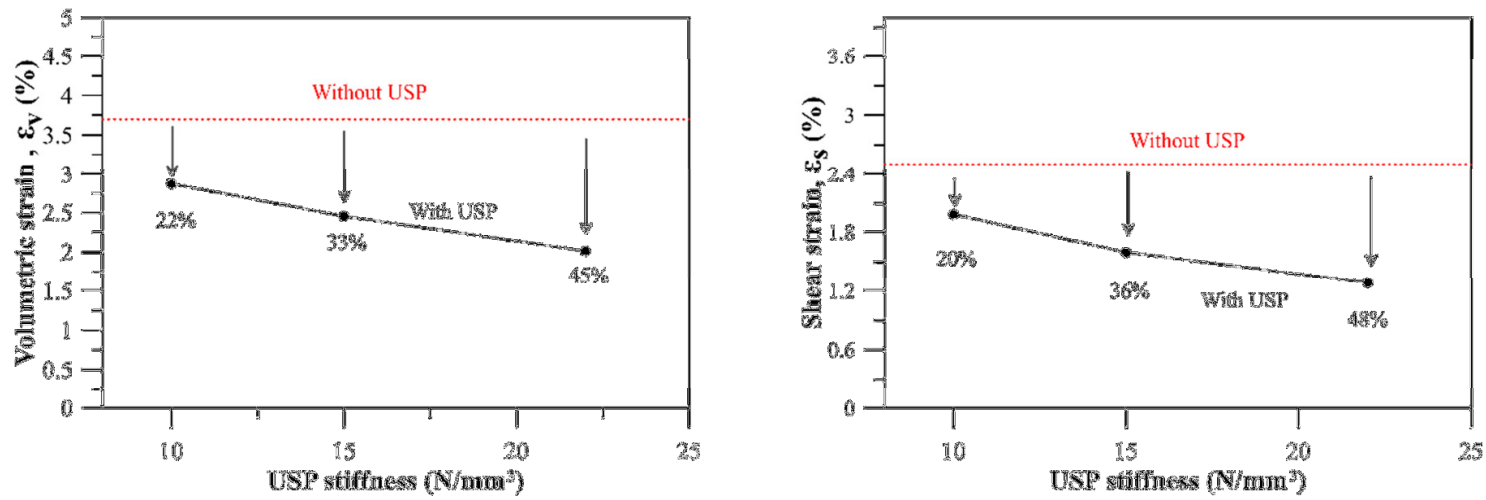

Figure 9: Influence of USP stiffness on: (a) Variations of volumetric strain; (b) Variations of shear strain; (c) Reduction of volumetric strain; and (d) Reduction of shear strain 
(a)

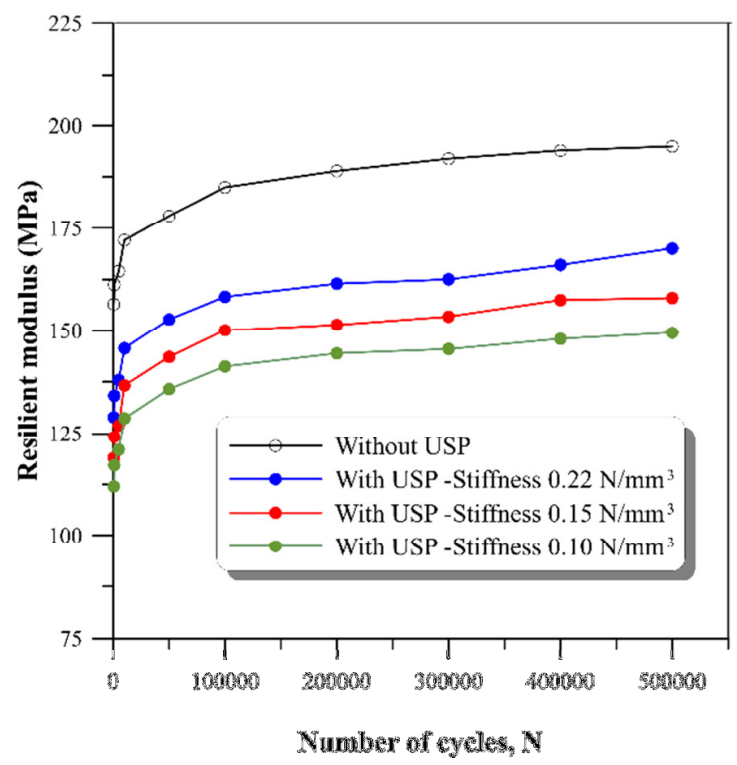

(b)

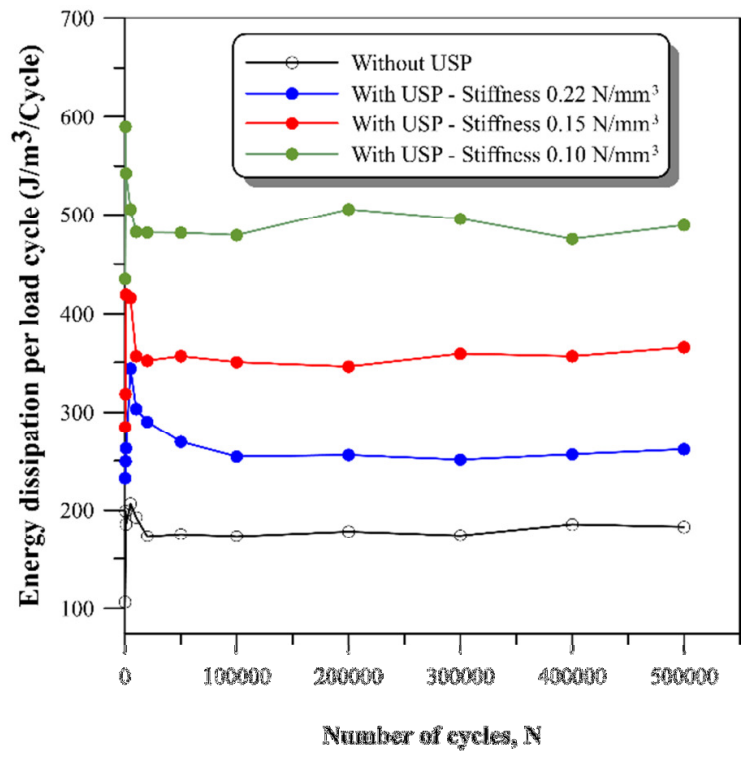

Figure 10: (a) Variation of resilient modulus, $M_{r}$ (b) Variation of energy dissipation, $E_{d}$ 


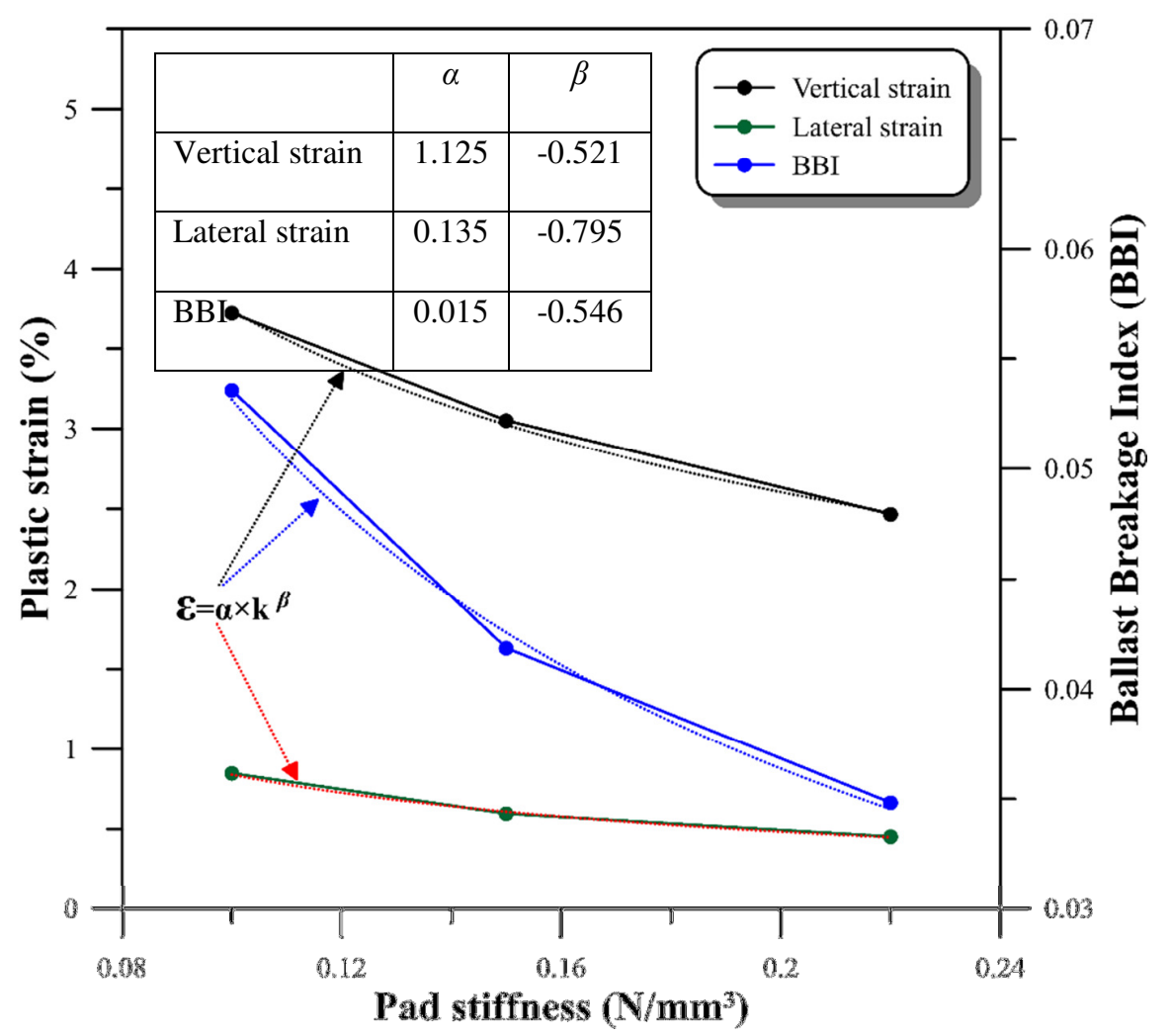

Figure 11: Variation of vertical, lateral strains and ballast breakage with varied stiffness of sleeper pad 


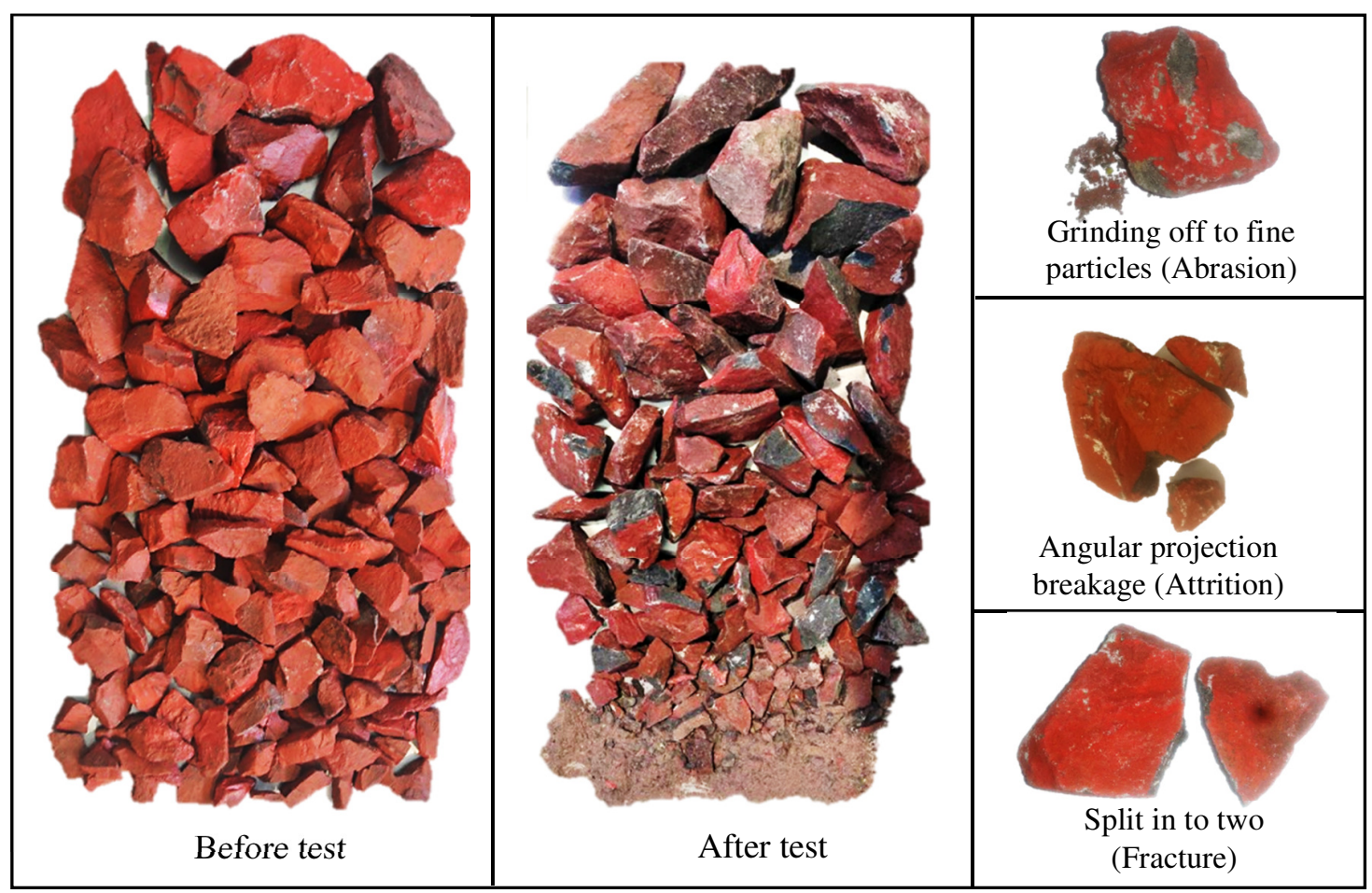

Figure 12: Ballast aggregates before and after the test, and types of particle breakage 
(a)

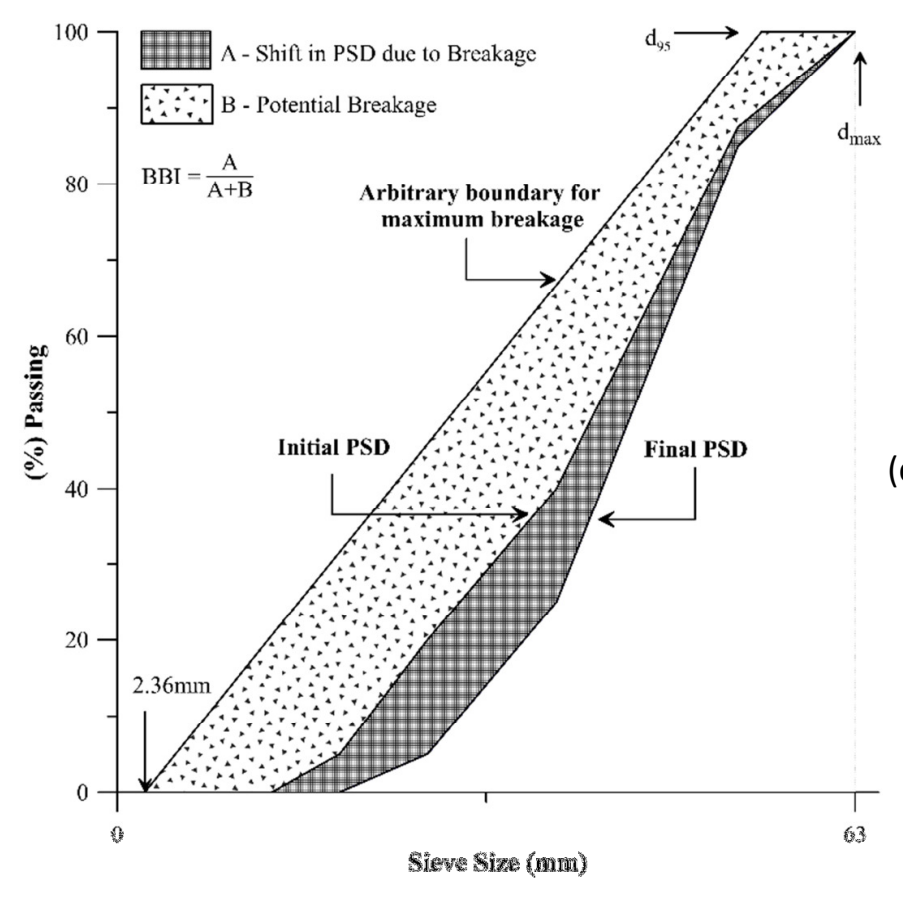

(b)

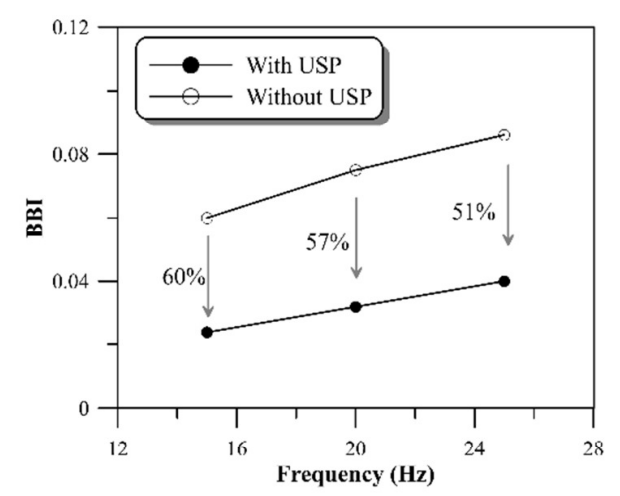

(c)

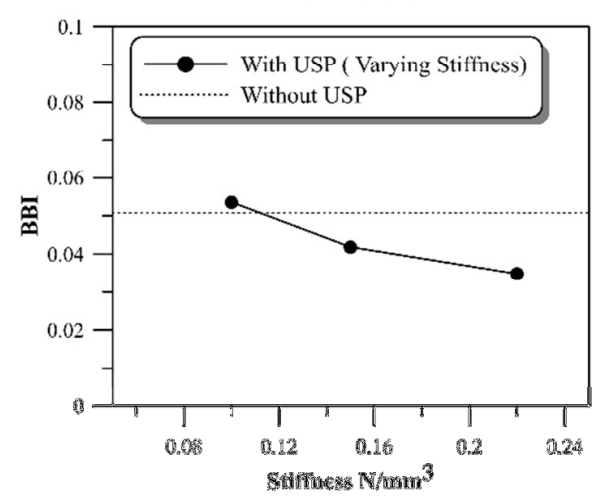

Figure 13: (a) Ballast breakage index (BBI); (b) Variation of BBI with frequency; and (c) Variation of BBI with USP stiffness 